\title{
The Impact of Atmosphere-Ocean-Wave Coupling on the Near-Surface Wind Speed in Forecasts of Extratropical Cyclones
}

\author{
Emanuele S. Gentile ${ }^{1}$ (D) Suzanne L. Gray ${ }^{1}$ (D) Janet F. Barlow ${ }^{1}$ (D) \\ Huw W. Lewis ${ }^{2}$ (D) John M. Edwards ${ }^{2}$ (D)
}

Received: 6 July 2020 / Accepted: 4 March 2021 / Published online: 20 April 2021

(C) The Author(s) 2021

\begin{abstract}
Accurate modelling of air-sea surface exchanges is crucial for reliable extreme surface windspeed forecasts. While atmosphere-only weather forecast models represent ocean and wave effects through sea-state independent parametrizations, coupled multi-model systems capture sea-state dynamics by integrating feedbacks between the atmosphere, ocean and wave model components. Here, we investigate the sensitivity of extreme surface wind speeds to airsea exchanges at the kilometre scale using coupled and uncoupled configurations of the Met Office's UK Regional Coupled Environmental Prediction system. The case period includes the passage of extra-tropical cyclones Helen, Ali, and Bronagh, which brought maximum gusts of $36 \mathrm{~m} \mathrm{~s}^{-1}$ over the UK. Compared with the atmosphere-only results, coupling to the ocean decreases the domain-average sea-surface temperature by up to $0.5 \mathrm{~K}$. Inclusion of coupling to waves reduce the 98 th percentile $10-\mathrm{m}$ wind speed by up to $2 \mathrm{~m} \mathrm{~s}^{-1}$ as young, growing wind waves reduce the wind speed by increasing the sea-surface aerodynamic roughness. Impacts on gusts are more modest, with local reductions of up to $1 \mathrm{~m} \mathrm{~s}^{-1}$, due to enhanced boundary-layer turbulence which partially offsets air-sea momentum transfer. Using a new drag parametrization based on the Coupled Ocean-Atmosphere Response Experiment 4.0 parametrization, with a cap on the neutral drag coefficient and reduction for wind speeds exceeding $27 \mathrm{~m} \mathrm{~s}^{-1}$, the atmosphere-only model achieves equivalent impacts on 10-m wind speeds and gusts as from coupling to waves. Overall, the new drag parametrization achieves the same $20 \%$ improvement in forecast 10 -m wind-speed skill as coupling to waves, with the advantage of saving the computational cost of the ocean and wave models.
\end{abstract}

Keywords Air-sea fluxes · Atmosphere-ocean-wave coupled model · Drag parametrization $\cdot$ Extreme surface wind speeds $\cdot$ Midlatitude cyclones

Emanuele S. Gentile

e.gentile@pgr.reading.ac.uk

1 Department of Meteorology, University of Reading, Earley Gate, P. O. Box 243, Reading RG6 $6 \mathrm{BB}, \mathrm{UK}$

2 Met Office, FitzRoy Road, Exeter EX1 3PB, UK 


\section{Introduction}

Every year several extra-tropical cyclones (ETCs) cross the British Isles, bringing extreme surface wind speeds that cause widespread damage of varying harshness to lives and livelihoods (Browning and Roberts 1994; Craig 2003; Hewston and Dorling 2011; Earl et al. 2017). The severity of the resulting damage can be estimated using the storm index first introduced by Klawa and Ulbrich (2003), which is proportional to the cube of exceedances of the local 98th percentile of wind speeds. Evaluation of the applicability of this index demonstrates that even relatively small forecast errors of extreme surface wind speeds can have a large impact on the accurate prediction and assessment of the severity of ETCs (Hewston and Dorling 2011; Earl and Dorling 2013). Thus, skillful forecasts of extreme surface wind speeds associated with ETCs are critical to providing actionable information to first-line responders as a basis for preparedness to act (Ricchi et al. 2017; Lewis et al. 2018). The potential importance of air-sea interaction in moderating surface wind speed has led to widespread interest in the development of numerical-weather-prediction (NWP) systems capable of representing air-sea surface exchanges with high fidelity (Janssen 2004; Lewis et al. 2019). Here we use the Met Office's UK Regional Atmosphere-Ocean-Wave Coupled Environmental Prediction (UKC4) system to explore the sensitivity of extreme surface wind speeds and gusts to the physical mechanisms underpinning air-sea interactions.

Although the magnitude of the near-surface wind speeds and gusts are controlled at the synoptic scale by the baroclinicity and associated large wind shear, which favours the formation of ETCs with large horizontal pressure gradients, the strengths are moderated by local mesoscale and convective-scale processes. These processes include the convectivescale vertical momentum exchange between the cloud layer and boundary layer, and the turbulent vertical mixing of heat, moisture, and momentum flux that controls the effect of the boundary-layer structure on the magnitude of near-surface wind speeds (Schultz et al. 2019). As turbulent eddies cannot be resolved by current NWP models, turbulent fluxes need to be parametrized (Lock et al. 2013). The parametrized turbulent fluxes that control the near-surface wind speed can be very sensitive to the surface-layer parametrization used due to the steep gradients of momentum, heat, and moisture at the base of the marine atmospheric boundary layer (MABL)(Janssen 2004; Ricchi et al. 2017; Lewis et al. 2019). Other boundary-layer processes such as moist convection and dry entrainment can dry the boundary layer, consequently increasing the evaporation rate of the ocean. While all these processes are important for the near-surface wind speed and gust magnitude, here we focus on air-sea momentum exchange and the way the sea-surface temperature (SST) is communicated to the atmosphere model; the roles of moist convection and processes at the top of the boundary layer are not considered.

The turbulent momentum flux at the air-sea interface is the focal point of theoretical studies that reveal the importance of dynamically evolving ocean waves in controlling the near-surface wind speed (Charnock 1955; Smith 1988; Smith et al. 1992; Janssen 2004). Turbulent fluctuations of atmospheric pressure induce, over the sea surface, small regular waves (Phillips 1957), which can continue to grow in height if forced by sufficiently high wind speeds (Miles 1957). As the young waves grow, they extract momentum and energy from the overlying airflow, acting in the MABL as roughness elements, which reduce the near-surface wind speed (Janssen 1989, 1991; Donelan 1982; Jenkins et al. 2012). However, the impact of ocean waves is not exclusively confined to the near-surface wind speed. Since ocean waves support turbulence generation, they are responsible for changing the amount of mixing within the MABL, which in turn modifies the air-sea turbulent fluxes (Donelan 
1982; Donelan et al. 1993) and the vertical wind-speed profiles across the MABL (Sullivan et al. 2008). At wind-wave equilibrium, when the waves are no longer growing, the MABL profiles can be well approximated by Monin-Obukhov similarity theory (MOST) (Sullivan et al. 2014). The theory accounts for the impact of waves and the deformation of the sea surface through surface exchange coefficients, including the neutral drag coefficient, whose parametrization requires no other knowledge of the sea state except that of the 10-m wind speed (Belcher and Hunt 1993; Cook and Renfrew 2014). By employing boundary-layer parametrizations based on MOST, atmosphere-only operational NWP models, including the Met Office's variable resolution model UKV (Tang et al. 2013), can be run without evolving the ocean and wave states, reducing the complexity of the simulated physics and therefore reducing the computational cost.

Over the past 50 years, measurements of the drag coefficient over the sea have yielded reliable information for wind speeds less than $20 \mathrm{~m} \mathrm{~s}^{-1}$. These measurements show that the neutral drag coefficient increases quasi-linearly with the wind speed, as predicted by MOST. However, large-eddy simulations have shown that MABL wind-speed profiles at extreme wind speeds deviate from those predicted by MOST theory, demonstrating that drag cannot be assumed to always grow linearly with wind speed (Sullivan et al. 2014). Laboratory experiments have shown that the drag coefficient saturates at $30 \mathrm{~m} \mathrm{~s}^{-1}$, while for wind speeds higher than $30 \mathrm{~m} \mathrm{~s}^{-1}$, observations over the ocean indicate a smooth decrease of the drag coefficient with wind speed (Powell et al. 2003). Donelan (2018) reconciled these results distinguishing between two different turbulent ow regimes: a linear increase of drag coefficient for wind speeds in the range of $2.5-30 \mathrm{~m} \mathrm{~s}^{-1}$ followed by a smooth decrease in the range of $30-50 \mathrm{~m} \mathrm{~s}^{-1}$, with the latter regime explaining the explosive deepening of Atlantic hurricanes. As near-surface wind speeds associated with the ETCs can approach those of hurricanes, it follows that both the steepness in the linear-drag regime and the decrease in the saturated-drag regime can affect the skill of wind speed forecasts. Over the last decade, a number of coupled multi-model simulation systems have been developed to directly integrate the feedbacks between the ocean and wave single-component models and the atmosphere-only models. These systems have shown potential for more accurate predictions of severe weather events, such as extreme surface wind speeds (Katsafados et al. 2016; Lewis et al. 2018). For example, Wahle et al. (2017) simulated a historical series of winter storms that cross the southern North Sea, demonstrating that coupling the Wave Model WAM (Komen et al. 1994), run at 5-km grid spacing, with the COnsortium for Smallscale MOdelling COSMO (Rockel et al. 2008), run at 10-km grid spacing, reduced wave heights and wind speeds by up to $8 \%$ and $3 \%$, respectively, with associated improvements in the forecast skill of the wind speed and wave height. Comparable reductions in wind speeds and wave heights were documented by Varlas et al. (2017) for a cyclonic event over the Mediterranean simulated using a two-way coupled system of the Weather Research and Forecasting atmosphere (Skamarock and Klemp 2008) and WAM wave models, both run at 10-km grid spacing; the associated improvements in the forecast skill for wave height and wind speed were $20 \%$ and $5 \%$, respectively.

Ricchi et al. (2017) performed a case study of a tropical-like cyclone in the Mediterranean sea, confirming that coupling improved the skill of extreme surface wind-speed forecasts compared with atmosphere-only simulations, but also finding that the atmosphere-only simulations with a suitable boundary-layer parametrization achieve improvements equivalent to those of coupling. In particular, they found that the sensitivity of the heat and momentum fluxes to parametrizations of surface roughness is greater than the sensitivity to air-sea coupling. The latter result highlights the need to consider the physical assumptions of coupling in NWP systems as well as the parametrizations embedded within the atmosphere-only model. 
In this context, the Met Office has developed a kilometre-scale-resolution coupledmodelling system, UKC4, (Lewis et al. 2018) for a domain focused on the UK and north-west shelf region. The UKC4 system enables assessment of the kilometre-scale sensitivity of rapidly varying meteorological fields, such as near-surface wind speeds, to the air-sea surface exchanges represented by atmosphere-ocean-wave coupling (Lewis et al. 2018, 2019).

The aim here is to quantify, in a case study, the sensitivity of extreme surface wind speeds to different coupled configurations and drag parametrizations using the UKC4 modelling system as a tool. The period 17-20 September 2018 provides a paradigmatic case study because it includes three intense ETCs that brought severe weather over the UK, with maximum recorded gusts of $36 \mathrm{~m} \mathrm{~s}^{-1}$. Four different configurations of the UKC4 system are used: two atmosphere-only configurations, one provided with the operational UKV drag parametrization and the other one with the Coupled Ocean-Atmosphere Response Experiment COARE 4.0 drag parametrization with the drag coefficient capped for wind speeds exceeding $27 \mathrm{~m} \mathrm{~s}^{-1}$ (Donelan 2018) and then decreasing for wind speeds exceeding $33 \mathrm{~m} \mathrm{~s}^{-1}$ (Hsu et al. 2017); a partially-coupled atmosphere-ocean configuration; and a fully-coupled atmosphere-ocean-wave configuration.

Below, in Sect. 2, the UKC4 regional coupled modelling system and the coupled and uncoupled configurations are described. In Sect. 3, the impacts of atmosphere-ocean and atmosphere-ocean-wave coupling are compared to the two different drag parametrizations employed by the atmosphere-only configurations and the resulting changes in the boundarylayer profiles and vertical structure of the storms are discussed. The forecast skill of the simulations is then evaluated by comparison to in situ observations, with conclusions given in Sect. 4.

\section{Methodology}

The UKC4 system is a regional coupled multi-model NWP system (Lewis et al. 2018), which incorporates models of the atmosphere [Met Office Unified Model MetUM (Walters et al. 2017)], land surface [the Joint UK Land Environment Simulator JULES (Best et al. 2011)], shelf-sea ocean [the Nucleus for European Modelling of the Ocean NEMO Madec 2016] and ocean surface waves [the WAVEWATCH $I I I^{\circledR}$ (WW3DG 2016)]. A feature of the system is the ability to set up different levels of coupling by connecting or excluding model components. The UKC4 domain is represented in Fig. 1.

\subsection{Model Components}

A brief description of the UKC4 model components is now given.

- Atmosphere component: based on the UKV configuration of the MetUM (Tang et al. 2013), this employs a variable resolution with $1.5 \mathrm{~km} \times 1.5 \mathrm{~km}$ horizontal grid cells in the inner region increasing to $1.5 \mathrm{~km} \times 4 \mathrm{~km}$ in the outer region and $4 \mathrm{~km} \times 4 \mathrm{~km}$ in the corners of the domain $(950 \times 1025$ grid cells $)$. The atmospheric model domain is nested within the global model. The model uses a hybrid height vertical coordinate system with 70 vertical levels and a lid at $40 \mathrm{~km}$. The SST lower boundary condition is provided by the Operational Sea Surface Temperature and Sea Ice Analysis [OSTIA (Donlon et al. 2012)], and persisted for the entire duration of a simulation. Surface ocean currents are initialized to zero so that the lower boundary is at rest. The effect of roughness from 

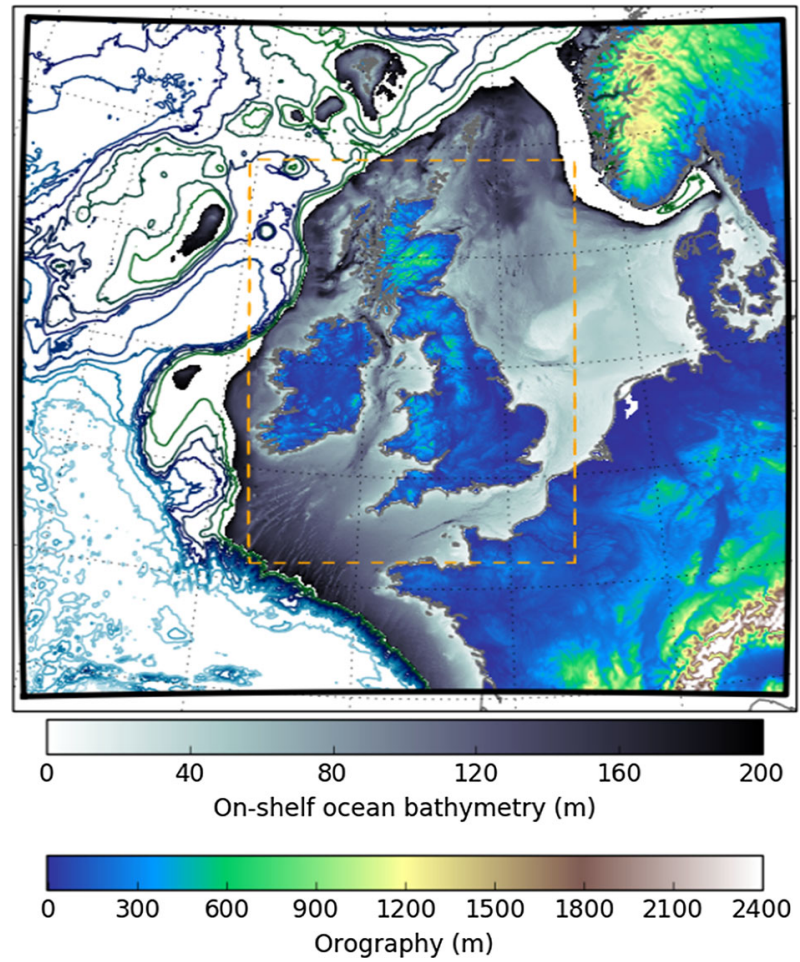

Fig. 1 The UKC4 domain (black boundary) used to define the atmosphere, ocean, and wave model components. The model orography and bathymetry are also shown. The upper colourbar relates to on-shelf bathymetry (depths $<200 \mathrm{~m}$ ), while contour lines are plotted in the open ocean every $500 \mathrm{~m}$ depth. The lower colourbar relates to the orography over land (heights $<2400 \mathrm{~m}$ ). The orange dashed box shows the approximate extent of the regular $1.5 \mathrm{~km} \times 1.5 \mathrm{~km}$ inner region of the atmospheric component grid

surface waves is specified setting the Charnock parameter to the constant operational UKV value of $\alpha=0.011$ across the whole domain.

- Land component: based on the JULES land-surface model, this component provides the exchanges of momentum, heat, and water between the land surface and the atmospheric boundary layer, and it shares the grid with the atmosphere component grid.

- Ocean component: based on the mesoscale eddy-resolving coastal ocean model [regional version of NEMO (Tonani et al. 2019)] this employs $1.5 \mathrm{~km} \times 1.5 \mathrm{~km}$ horizontal grid cells throughout the domain $(1458 \times 1345$ grid cells $)$. The vertical domain is discretized into 51 vertical levels. The ocean model is initialized from the operational ocean model [the Atlantic Margin Model AMM15 (Graham et al. 2018)].

- Wave component: based on the WAVEWATCH III third-generation spectral-wave model, this shares its model grid with the ocean model. The spectral boundary conditions are provided by the archived operational global wave model output. 


\subsection{Basis of the Coupling Parametrizations}

A brief description of the coupling parametrizations used by the UKC4 system follows. These are consistent with those employed in the previous model version, UKC3, and a full discussion of those can be found in Lewis et al. (2018, 2019).

The UKC4 system parametrizes momentum, heat, and moisture air-sea turbulent fluxes by assuming that MOST holds in the surface layer. Therefore, in the surface layer, the dependence of wind speed, $U$, on height, $z$, is parametrized by the log-law

$$
U=\frac{u_{*}}{k}\left[\ln \left(\frac{z}{z_{0}}\right)-\Psi_{m}\right],
$$

where $u_{*}$ is the friction velocity, $z_{0}$ the aerodynamic roughness length, $\Psi_{m}$ is the MoninObukhov stability function for momentum, and $k=0.4$ is the von Kármán constant. In the UKC4 approach, Eq. 1 is used to compute the $10-\mathrm{m}$ wind speed, $U_{10}$, which, together with the standard deviation of their distribution, $\sigma_{u}$, is used to parametrize the gust strength $U_{g u s t}$ following Panofsky et al. (1977) as

$$
U_{\text {gust }}=U_{10}+\sigma_{u} \frac{1}{k} \ln \left(\frac{5 \mathrm{e}^{k c_{\text {ugn }}}+z_{0(\text { eff })}}{5+z_{0(\text { eff })}}\right),
$$

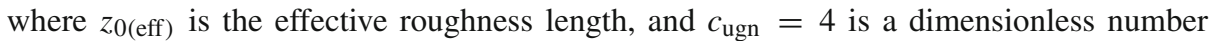
determined from the universal turbulence spectra (Beljaars 1987). The standard deviation is computed following

$$
\sigma_{u}= \begin{cases}2.29 u_{*}\left(1-\frac{z \mathrm{blh}}{24 L}\right)^{\frac{1}{3}} & L<0 \\ 2.29 u_{*} & L>0,\end{cases}
$$

which depends on three different boundary-layer characteristics: the friction velocity $u_{*}$, the boundary-layer height $z_{\mathrm{blh}}$, and the Obukhov length $L$.

Over the sea, the roughness length, $z_{0}$, depends on both the atmospheric surface-layer flow and the underlying surface wave state, as described by the generalized Charnock formula

$$
z_{0}(\text { sea })=\frac{0.11 v}{u_{*}}+\frac{\alpha}{g} u_{*}^{2}
$$

where $v=14 \times 10^{-6} \mathrm{~m}^{2} \mathrm{~s}^{-1}$ is the kinematic viscosity of air, and $\alpha$ is the Charnock parameter (Charnock 1955; Smith 1988).

In the UKC4 uncoupled atmosphere-only mode, $z_{0}$ is computed using the empirical constant $\alpha=0.011$ for the Charnock coefficient. When the atmosphere model is coupled to the wave model, the latter calculates a spatially varying Charnock parameter field and exchanges it hourly with the atmosphere component. The transfer coefficient for the momentum flux, $C_{\mathrm{D}}$, also termed the drag coefficient, is parametrized at the ocean surface as a function of atmospheric stability and roughness length $z_{0}$ by

$$
C_{\mathrm{D}}=\left[\frac{k}{\ln \left(\frac{z}{z_{0}}\right)-\Psi_{m}}\right]^{2},
$$

and it is used to calculate the friction velocity, $u_{*}$, as $u_{*}=\sqrt{C_{\mathrm{D}}} U_{10}$, which, together with the value of the roughness length $z_{0}$, determines the wind speed in Eq. 1. Since latent heat fluxes are dominant over the sea, the UKC4 approach takes the roughness length for scalar fluxes $z_{0 h}$ (sea) as the roughness length for moisture flux, $z_{0 q}$, and computes it by parametrizing the 
Table 1 Summary of the four configurations of the UKC4 multi-model system

\begin{tabular}{|c|c|c|c|c|}
\hline Name & Components & Mode & Description & Node hours \\
\hline Adrag1 & Atmosphere only & Uncoupled & $\begin{array}{l}\text { Global OSTIA, } \\
\text { SST boundary } \\
\text { condition } \\
\text { persisted and } \\
\text { UKV regional } \\
\text { drag } \\
\text { parametrization }\end{array}$ & 32 \\
\hline Adrag2 & Atmosphere only & Uncoupled & $\begin{array}{l}\text { Global OSTIA, } \\
\text { SST boundary } \\
\text { condition } \\
\text { persisted and } \\
\text { new drag } \\
\text { formulation } \\
\text { based on the } \\
\text { COARE 4.0 } \\
\text { drag } \\
\text { parametrization } \\
\text { with the } \\
\text { Donelan (2018) } \\
\text { cap and } \\
\text { reduction at high } \\
\text { wind speeds }\end{array}$ & 32 \\
\hline $\mathrm{A}-\mathrm{O}$ & Atmosphere-Ocean & Partially coupled & $\begin{array}{l}\text { Atmosphere- } \\
\text { ocean coupling, } \\
\text { no wave } \\
\text { interactions }\end{array}$ & 35 \\
\hline $\mathrm{A}-\mathrm{O}-\mathrm{W}$ & Atmosphere-Ocean-Wave & Fully coupled & $\begin{array}{l}\text { Atmosphere- } \\
\text { ocean-wave, } \\
\text { fully coupled }\end{array}$ & 43 \\
\hline
\end{tabular}

For each configuration name, the model components involved, the coupling mode, the description of some of the key features, and the computational cost in node hours per forecast simulation day are given. All configurations were run on the Met Office and NERC joint supercomputer system (MONSooN)

roughness length, $z_{0}$, according to the surface-divergence theory from Csanady (2001), as explained by Edwards (2007)

$$
z_{0 h}(\text { sea })=\max \left(7 \times 10^{-8}, \frac{2.56 \times 10^{-9}}{z_{0}}\right) .
$$

To represent aerodynamically smooth conditions that occur for low wind speeds, $z_{0 h}$ (sea) is computed as $z_{0 h}$ (sea) $=\max \left(\tilde{z}_{0 h}(\mathrm{sea}), 2.52 \times 10^{-10} / u_{*}\right)$ where $u_{*}$ is in $\mathrm{m} \mathrm{s}^{-1}$ and $\tilde{z}_{0 h}$ (sea) is calculated according to Eq. 5. Then, over the ocean, the scalar transfer coefficient, $C_{h}$, can be expressed as a function of atmospheric stability, roughness length $z_{0}$, and scalar roughness length $z_{0 h}$ as

$$
C_{h}=\frac{k^{2}}{\left[\ln \left(\frac{z}{z_{0}}\right)-\Psi_{m}\right]\left[\ln \left(\frac{z}{z_{0 h}}\right)-\Psi_{h}\right]} .
$$

Therefore, the air-sea turbulent momentum flux, $\tau_{0}$, sensible heat flux, $H_{0}$, and latent heat flux, $E_{0}$, are parametrized according to

$$
\frac{\tau_{0}}{\rho_{0}}=C_{\mathrm{D}}|\Delta \mathbf{v}|^{2}
$$




$$
\frac{H_{0}}{c_{p} \rho_{0}}=-C_{h} U\left(\Delta T+\frac{g}{c_{p}}\left(z_{1}+z_{0}-z_{0 h}\right)\right),
$$

and

$$
\frac{E_{0}}{\rho_{0}}=-C_{h} U \Delta q,
$$

where $\rho_{0}$ is the air surface density, $c_{p}$ is the specific heat capacity at constant pressure, $z_{1}$ is the height of the bottom model layer above the surface, and $\Delta \mathbf{v}, \Delta T$, and $\Delta q$ are the vertical differences between the surface and bottom model level of the velocity vector $\mathbf{v}$, temperature $T$, and specific humidity $q$ fields, respectively. In particular, the surface specific humidity is $98 \%$ of its saturation value at SST due to salinity.

\subsection{Experimental Configurations}

Four different configurations of the UKC4 system were set up (whose characteristics are summarized in Table 1): two atmosphere-only configurations which use different parametrizations of the neutral drag coefficient (hereafter Adrag1 and Adrag2); a partially-coupled atmosphere-ocean configuration (hereafter A-O); and a fully-coupled atmosphere-oceanwave configuration (hereafter A-O-W). The JULES land-surface model is coupled to the MetUM atmosphere model in all configurations.

The two atmosphere-only configurations (Adrag1 and Adrag2) use the MetUM only. The Adrag1 configuration, referred to as UKA4g in Lewis et al. (2018, 2019), uses the regional UKV drag parametrization: $z_{0}$ in Eq. 4 is computed at each grid cell using a constant Charnock parameter $\alpha=0.011$, which is independent of the wind speed. As illustrated in Fig. 2a, the Adrag1 parametrization uses an approximately linear growth of the neutral drag coefficient, $C_{\mathrm{D}}$, for 10 -m wind speeds greater than $\approx 5 \mathrm{~m} \mathrm{~s}^{-1}$. The Adrag2 configuration uses a new drag parametrization which combines the COARE 4.0 parametrization at lower wind speeds with the Donelan (2018) cap and reduction of the value of the drag coefficient at higher wind speeds. In contrast to the UKV drag parametrization, the COARE 4.0 scheme, based on many in situ observations, models a linear growth of the Charnock parameter $\alpha$ with wind speeds, capped at $22 \mathrm{~m} \mathrm{~s}^{-1}$, which effectively models an empirical weak dependence of the parameter $\alpha$ on the wave age. In particular, Fig. 2a shows that the neutral drag coefficient, $C_{\mathrm{D}}$, modelled by the Adrag2 configuration increases steeply for wind speeds from 2.57$27 \mathrm{~m} \mathrm{~s}^{-1}$, before plateauing at $\approx 3 \times 10^{-3}$ for wind speeds from $27-33 \mathrm{~m} \mathrm{~s}^{-1}$, before declining and flattening out at $\approx 2 \times 10^{-3}$ for wind speeds more than $55 \mathrm{~m} \mathrm{~s}^{-1}$. The plateau value was tuned from the recommended Donelan (2018) value of $C_{\mathrm{D}} \approx 1.3 \times 10^{-3}$ to $C_{\mathrm{D}} \approx 2 \times 10^{-3}$, consistent with findings from Hsu et al. (2017) and still within the error bars of the Donelan (2018) drag coefficient. Note that the variation of the drag coefficient $C_{\mathrm{D}}$ with wind speeds exceeding $31 \mathrm{~m} \mathrm{~s}^{-1}$ is not relevant for this case study. For consistency, the Adrag2 configuration uses, over the ocean, a scalar (moisture) transfer coefficient based on the COARE4.0 parametrization and then a cap and decrease for wind speeds greater than $27 \mathrm{~m} \mathrm{~s}^{-1}$. As can be noted from Fig. $2 \mathrm{~b}$, the Adrag2 $C_{h}$ parametrization is relatively close to that of Adrag1 until $45 \mathrm{~m} \mathrm{~s}^{-1}$, and thus likely to lead to negligible impacts on ocean heat and moisture fluxes for the range of wind speeds simulated in this case study.

The partially coupled A-O configuration has two-way coupling of the MetUM and NEMO models at hourly frequency. The SST and the surface ocean currents are sent by NEMO to the MetUM, which uses the SST and ocean currents data as boundary conditions and in turn sends the scalar and momentum surface fluxes, pressure and velocity fields to the NEMO model. 

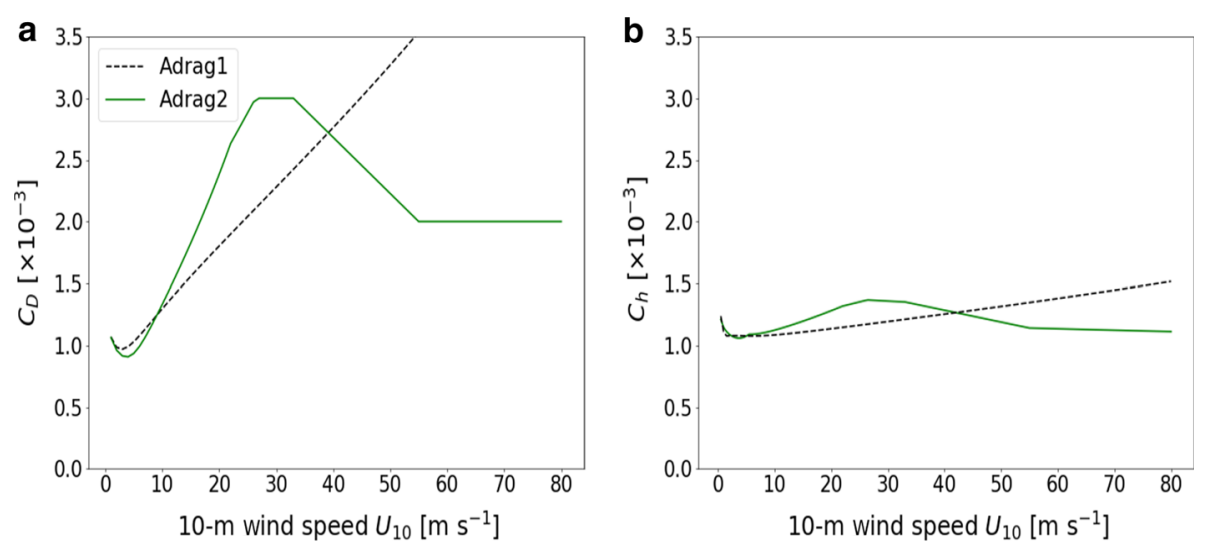

Fig. 2 The Adrag1 (black) and Adrag2 (green) parametrizations of the a neutral drag coefficient and $\mathbf{b}$ transfer coefficient for scalar flux (moisture) in neutral conditions as a function of the 10 -m wind speed, $U_{10}$. a The dashed black line represents the operational UKV drag parametrization employed in the Adrag1 configuration, while the solid green line represents the COARE 4.0 parametrization with the Donelan (2018) cap at $C_{\mathrm{D}}=$ $3.0 \times 10^{-3}$ and decrease of drag values at high wind speeds to $C_{h}=2.0 \times 10^{-3}$ employed in the Adrag2 configuration. $\mathbf{b}$ The dashed black line represents the operational UKV moisture-flux parametrization employed in the Adrag1 configuration, while the solid green line represents the COARE 4.0 moisture parametrization with a cap at $C_{h}=1.4 \times 10^{-3}$ and then a decrease to $C_{h}=1.1$ employed in Adrag2. The approximately linear trend in Adrag1 drag and scalar-flux parametrization continues indefinitely above $C_{\mathrm{D}}=3.5 \times 10^{-3}$ and $C_{h}=1.6 \times 10^{-3}$ though not shown

The A-O configuration uses the same regional UKV drag parametrization used by the Adrag1 configuration. Finally, the fully coupled A-O-W configuration includes coupling to waves in addition to coupling to the ocean by implementing two-way coupling between the MetUM, NEMO, and WAVEWATCH III models. The MetUM sends the velocity field to both NEMO and WAVEWATCH III, with the latter providing the MetUM a spatially and temporally varying, wave-dependent Charnock parameter $\alpha$ used by the atmosphere component in Eq. 3 to update the aerodynamic surface-roughness estimate. All the simulations were initialized at 0000 UTC 16 September 2018 and run until the 0000 UTC 21 September 2018. However, the analysis of meteorological fields of interest started from 0000 UTC on 17 September 2018 .

\subsection{Evaluation of Model Forecast Skill}

To assess the forecast skill of the UKC4 experiments, outputs of different model configurations were compared to a variety of in situ observations sourced from the Met Office's meteorological database, accessed from the UK Centre for Environmental Data Analysis. The Met Office meteorological database includes land observations, collected by automatic weather stations managed by the national weather services operating across Europe, and ocean observations, provided by offshore oil installations, drifting buoys, moored buoys, and ships. Three different meteorological fields were considered: mean 10-m wind speed, $10-\mathrm{m}$ gust, and SST. The mean 10-m wind speed is measured at $10-\mathrm{m}$ height and obtained by averaging the wind fluctuations (sampled every $0.25 \mathrm{~s}$ due to their turbulent nature) over the 10 -min period leading up to the hourly reporting time. The 10 -m gust is the maximum three-second average wind speed recorded over the 10 -min period at $10-\mathrm{m}$ height. 
Some issues were addressed to effectively use the large amount of data available. First, SST data taken by ships and fed into the MetDB database were incomplete due to being transmitted from changing locations along ship tracks. Thus, only sites that recorded the SST data for at least $75 \%$ of the case-study duration, such as oil platforms and stationary ships, were considered for comparison to simulated results, following Lewis et al. (2018). Second, similarly to the SST observations, the gust observations collected over the sea were intermittent and therefore the same rejection threshold of the SST datasets was applied. In contrast, due to the much greater availability of temporally complete $10-\mathrm{m}$ wind series from observation sites, only those data were selected as this provided a sufficient number of different observation locations.

The relative forecast skill between two model configurations is quantified by calculating the relative root-mean-square error $\left(R M S E_{r e l}\right)$ over the four-day duration of the case study, defined as

$$
\begin{aligned}
R M S E_{\mathrm{rel}} & =\frac{R M S E_{X}-R M S E_{Y}}{R M S E_{Y}} \\
& =\left(\sqrt{\frac{\sum(O-X)^{2}}{n}} / \sqrt{\frac{\Sigma(O-Y)^{2}}{n}}\right)-1,
\end{aligned}
$$

where $O$ are the in situ observations used for comparison, $n$ is the number of in situ observations, and $X$ and $Y$ are the model outputs at the observation locations from two different configurations of the UKC4 system.

\section{Results and Discussion}

Below, Sect. 3.1 provides a description of the extreme weather conditions affecting the UK from 17-20 September 2018 along with the numerical bias of the atmosphere-only Adrag1 configuration. The following subsections analyze and compare the impacts of the Adrag1, Adrag2, and coupled configurations on the SST, 10-m wind speeds, and gusts for the surface fields, boundary-layer structure, and forecast biases.

\subsection{Synoptic Overview of Case Study and Adrag1 Atmosphere-only Simulation Biases}

The sensitivity of extreme surface wind speeds to air-sea surface exchange is investigated in the extreme weather conditions brought by Helene, Ali, and Bronagh as they crossed the UK from 17-20 September 2018. Helene transitioned from a hurricane to an ETC on 17 September 2018 (Fig. 3a), accompanied by increasing pressure gradients with fronts forming, and then approached and made landfall on Ireland, and subsequently on the UK, on 18 September 2018 (Fig. 3b).

On 19 September 2018 (Fig. 3c), while Helene decayed after crossing the North Sea, the track of Ali crossed Ireland and the UK prior to Ali's intensification over the North Sea. On the last day of the case study (Fig. 3d), while Ali crossed Norway, Bronagh approached the UK. Of the three ETCs, Ali had the lowest central mean sea level pressure of $969 \mathrm{hPa}$ over the North Sea at 1800 UTC 19 September (not shown), with maximum gusts peaking at $36 \mathrm{~m} \mathrm{~s}^{-1}$ over the North of the UK (MetOffice 2018).

As the most severe weather conditions occurred between 0000 UTC 19 September 2018 and 0000 UTC 20 September 2018, this time period was chosen to explore the bias of the 

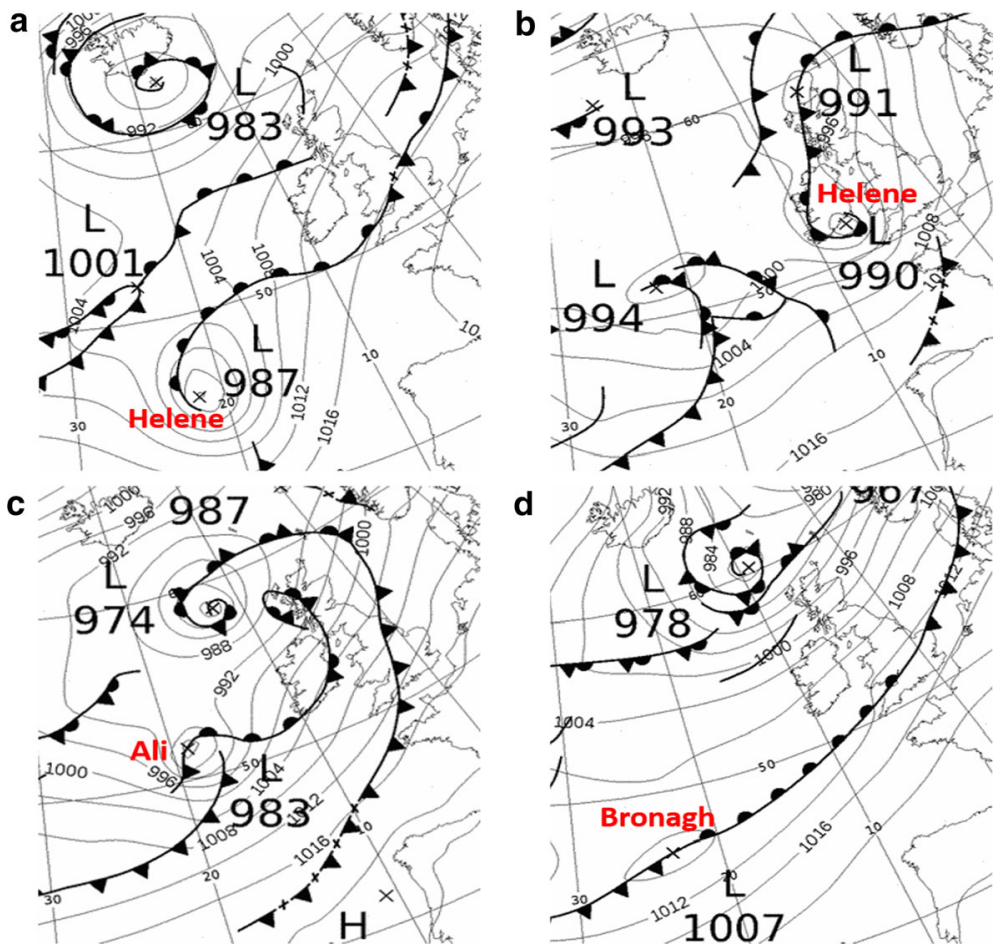

Fig. 3 Surface mean sea level pressure 0000 UTC analysis maps (hPa) for a 17, b 18, c 19, and d 20 September 2018. The maps are derived from Met Office's surface analyses archive, (C) Crown Copyright

uncoupled atmosphere-only Adrag1 simulation under extreme wind speeds. Observed 10-m wind speeds, 10-m gusts and SSTs are overlaid on the corresponding Adrag1 simulations in Fig. 4a, c, e and this reveals that the Adrag1 configuration overestimates all three fields at most of the observation sites. For example, over the North Sea, 10-m wind speeds are overestimated by up to $5 \mathrm{~m} \mathrm{~s}^{-1}$ while SST values are overestimated by up to $1.5 \mathrm{~K}$. The biases for 10-m wind speed, gust, and SST fields depicted in Fig. 4b, d, f are consistent with Lewis et al. (2019), who reported results over a longer time period relative to a month-long autumn case study. The size of the bias across the domain suggests that the atmosphere-only Adrag1 forecast may not provide a satisfactory representation of the air-sea interactions at high wind speeds.

\subsection{Impact of Coupling and Using a New Drag Parametrization on 10-m Wind Speed and Sea-Surface Temperature}

For comparisons of the simulation results to be meaningful (given the limited domain and time period), the tracks and structures of the ETCs that occurred during the case study must not diverge strongly. The tracks and structures must also compare reasonably well with analyses for a sensible discussion of forecast bias and skill. Comparison of all the four UKC4 simulations at 1800 UTC 19 September, when Ali crossed the North Sea and the wind speeds were highest, revealed reassuringly small differences (not shown). The low-pressure centres of Ali in the fully coupled atmosphere-ocean-wave A-O-W and uncoupled atmosphere- 

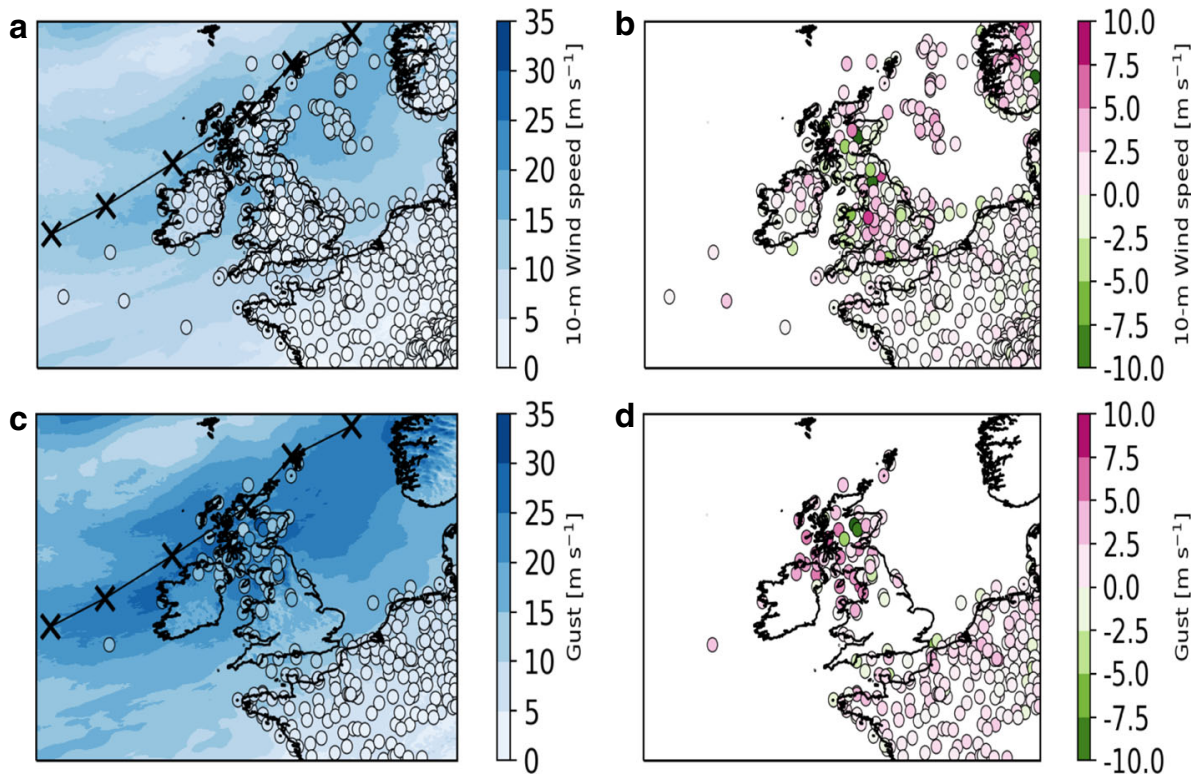

10.0

7.5

5.0

$-2.5$

0.0

$-2.5$

$-5.0$

$-7.5$

$-10.0$
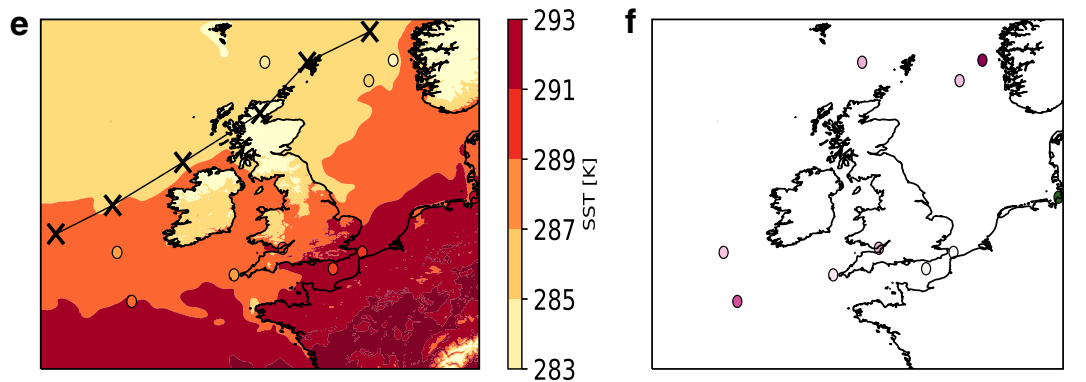

1.0
-0.8
-0.6
-0.4
-0.2
-0.0
-0.2
-0.4
-0.6
-0.8
-1.0

Fig. 4 a, b Maps of a coloured circles showing observed mean 10-m surface wind speed (581 stations) overlaying the corresponding field from the atmosphere-only Adrag1 simulation, and $\mathbf{b}$ coloured circles showing the simulated minus observed difference in mean $10-\mathrm{m}$ wind speed. $\mathbf{c}, \mathbf{d}$ and $\mathbf{e}, \mathbf{f}$ are the same as a, b but for gusts (255 stations) and SST (10 stations), respectively. The panels show averages of hourly data from 0000-2300 UTC 19 September 2018. The black line joining the crosses in each of the left-column panels represents the track of Ali, diagnosed from the Adrag1 run, with the crosses indicating the position of the mean sea-level-pressure minimum every $4 \mathrm{~h}$, starting at 0000 UTC 19 September 2018. Ali is tracked until it exits the model domain

only Adrag2 simulations were both shifted by approximately $20 \mathrm{~km}$ eastward compared with the position of the low-pressure centre in the partially coupled atmosphere-ocean A$\mathrm{O}$ and uncoupled atmosphere-only Adrag1 simulation. The intensity of Ali was slightly reduced in these simulations with an increase of the mean sea-level-pressure minimum from $\approx 966.2 \mathrm{hPa}$ (Adrag1 and A-O) to $\approx 967.7 \mathrm{hPa}(\mathrm{A}-\mathrm{O}-\mathrm{W}$ and Adrag2). A less pronounced pressure minimum is also systematically observed across the case study simulation days, with the maximum difference being up to $2 \mathrm{hPa}$. This behaviour in the $\mathrm{A}-\mathrm{O}-\mathrm{W}$ and Adrag2 configurations is attributed to the enhanced momentum-transfer coefficients (as discussed in Sect. 3.3) leading to more frictional drag at the air-sea interface and so enhanced Ekman pumping. Lionello et al. (1998), Doyle (2002) and Varlas et al. (2017) reported similar pressure reductions in cyclones when using wave coupling in simulations. 

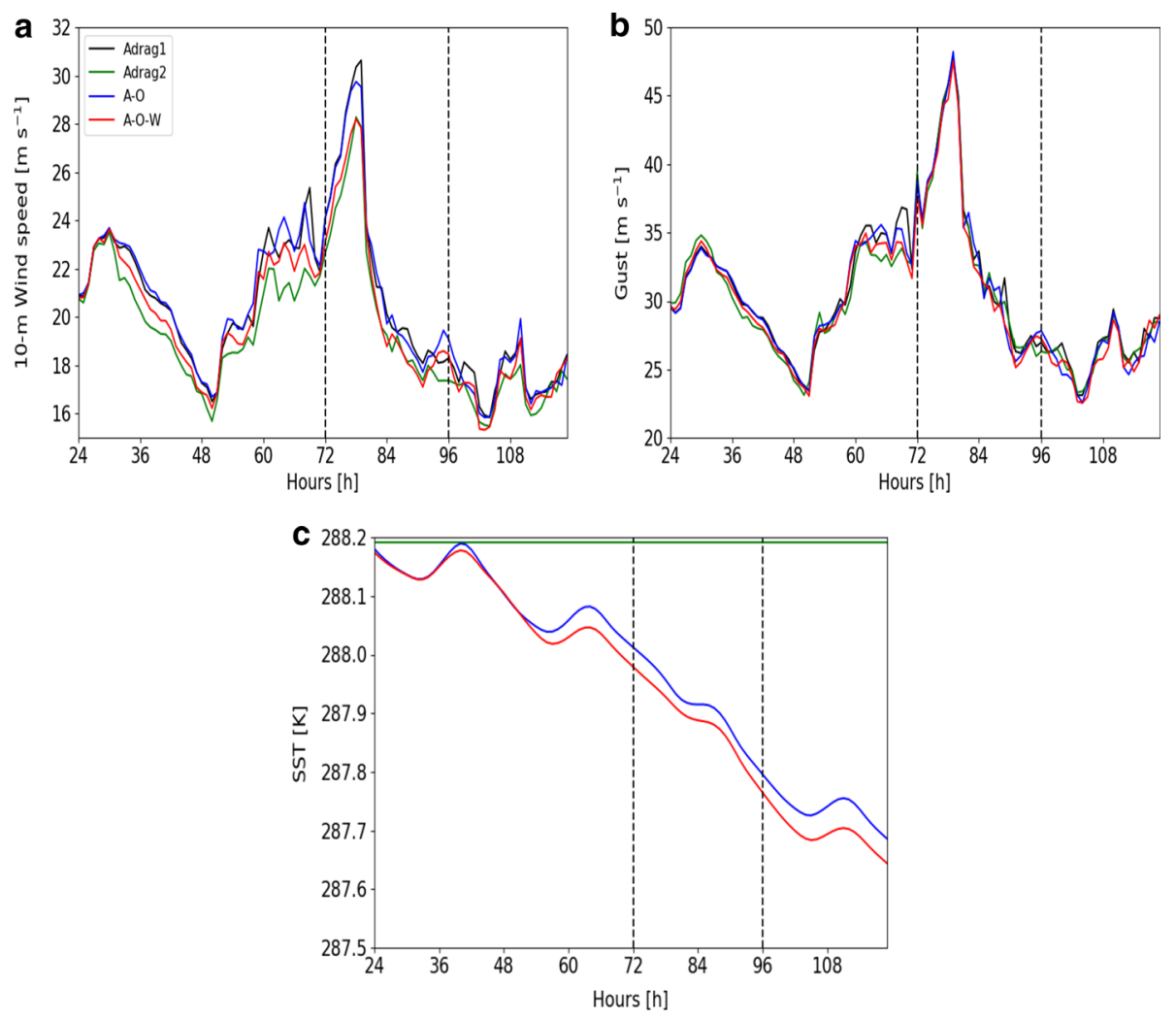

Fig. 5 Time series for 17-20 September 2018 of a 98th percentile 10-m wind speeds, b 98th percentile gusts, and $\mathbf{c}$ mean SST for the Adrag1 (black), Adrag2 (green), A-O (blue), and A-O-W (red) configurations and sea-only grid points. Adrag2 and Adrag1 SST values are identical and thus overlap in c. Vertical dashed lines at $+72 \mathrm{~h}$ and $+96 \mathrm{~h}$ indicate the start and end of 19 September

To focus on the low-level-jet regions in the ETCs, where air-sea interactions are strongest, we consider the 98th percentile 10-m wind speed and gust. Figure 5 shows time series of sea-only 98th percentile 10-m wind speeds, 98th percentile gusts, and mean SSTs for the different simulations averaged across the UKC4 domain. The 10-m wind speeds and gusts follow a similar pattern in all the UKC4 model configurations used here, peaking at the same time on 19 September 2018 when storm Ali brought extreme weather conditions over the UK (Fig. 5a, b).

As the 98th percentile $10-\mathrm{m}$ wind speeds increase over time, the partially coupled A-O simulation closely follows the atmosphere-only Adrag1 simulation, with the wind speeds peaking at 30.3 and $30.6 \mathrm{~m} \mathrm{~s}^{-1}$, respectively, at 0600 UTC on 19 September 2018 (see Fig. 5a). The 98th percentile of the A-O-W and Adrag2 10-m wind speeds are consistently lower than those simulated by Adrag 1 and A-O with maximum differences of up to $2 \mathrm{~m} \mathrm{~s}^{-1}$ at peak time. Prior studies of Wahle et al. (2017) and Lewis et al. (2019) documented a similar reduction of the 10-m wind speed, attributing it to the impact of atmosphere-oceanwave coupling. However, the close correspondence between Adrag2 and A-O-W results in Fig. 5a suggests that Helene, Ali, and Bronagh extreme surface wind speeds are equally sensitive to the Adrag2 new drag parametrization and to coupling to waves. In comparison, 
Fig. 5b shows that there is much less sensitivity of simulated gust values to the change in drag parametrization, and coupling to ocean and waves: Adrag1 and A-O peak gusts reach $47.7 \mathrm{~m} \mathrm{~s}^{-1}$ and A-O-W and Adrag2 reach $47.2 \mathrm{~m} \mathrm{~s}^{-1}$ at 0600 UTC on 19 September 2018. Compared to the A-O results, the slight reduction of $0.5 \mathrm{~m} \mathrm{~s}^{-1}$ in 98 th percentile of the A-O-W and Adrag2 simulated gusts could be accounted for by the reduction of 10-m wind speed upon coupling to waves and change in the drag parametrization.

The SSTs in the A-O and A-O-W simulations generally decrease with time by more than $0.5 \mathrm{~K}$ over the five days (Fig. $5 \mathrm{c}$ ). This reduction contrasts with the constant SSTs in the two atmosphere-only configurations. The near overlap of the SSTs produced by the A-O and A-O-W simulations reveals that, in this case, SST changes are primarily a consequence of the ocean coupling rather than the additional wave coupling, as also found by Lewis et al. (2018). Since the ocean is slightly stably stratified after surface heating through the summer, the oceanic mixing modelled by the ocean component implies surface cooling, consistent with earlier remarks.

To distinguish the impacts of coupling to the ocean from that of coupling to waves, we first compared the mean 10-m wind speed, gust, and SST differences between the A-O and Adrag1 approaches to isolate the impact of ocean feedbacks, and then between the A-O$\mathrm{W}$ and $\mathrm{A}-\mathrm{O}$ to isolate the impact of waves feedbacks. The left column in Fig. 6 shows maps of the differences between the A-O and Adrag1 simulations, while the right column shows differences between $\mathrm{A}-\mathrm{O}-\mathrm{W}$ and $\mathrm{A}-\mathrm{O}$ simulations, all averaged over the day when the most intense ETC, Ali, crossed the UK. The largest magnitude for the 10-m wind-speed differences between the A-O and Adrag1 simulations are found to the north of Ali's track, possibly associated with slightly different positioning of the bent-back front (i.e. different frontal structure) in the two simulations (Fig. 6a). However, the overall lack of coherency of the wind-speed differences is consistent with the negligible impact of ocean coupling seen in the domain-average time series (Fig. 5a). In contrast, compared with the 10-m wind speed in the partially coupled A-O simulation, the fully coupled A-O-W 10-m wind speeds are consistently decreased, by up to $2 \mathrm{~m} \mathrm{~s}^{-1}$, in the high-wind-speed region extending south of the track of Ali (Fig. 6b). Also, gusts are generally decreased by coupling to both the ocean and additionally to waves south of Ali's track (Fig. 6c, d), particularly in the North Sea, although only by up to $1 \mathrm{~m} \mathrm{~s}^{-1}$. Figure 6e, f, consistent with the results shown in Fig. 5c, indicates that the dominant impact of coupling on SSTs is the result of coupling to the ocean component with reductions across most of the ocean regions peaking at $\approx 2.2 \mathrm{~K}$. The additional impact of coupling to the wave component is smaller and localized with a $0.5-\mathrm{K}$ increase in the Dogger Bank region, characterized by shallow bathymetry, and a $0.5-\mathrm{K}$ decrease near the southern boundary of the model domain (see Fig. 6f).

\subsection{Impact of Coupling and Using a New Drag Parametrization on Boundary-Layer Characteristics}

The impact of coupling and using the new drag parametrization Adrag2 on boundary-layer characteristics is assessed by comparing simulated boundary-layer profiles at a point in the North Sea south of the track of Ali, where the wind speed reduction in the A-O-W simulation compared wth the Adrag1 simulation (Fig. 6b) is largest at 1800 UTC on 19 September 2018. Figure 7a shows that the selected point (cyan star) lies within Ali's cold sector, behind the cold front that stretches from Norway to southern England and characterized by a MABL height of $\approx 1.2 \mathrm{~km}$, in contrast to a depth of $\approx 0.4 \mathrm{~km}$ in the warm sector. This marked change in boundary-layer height, and associated stability characteristics, on crossing the 

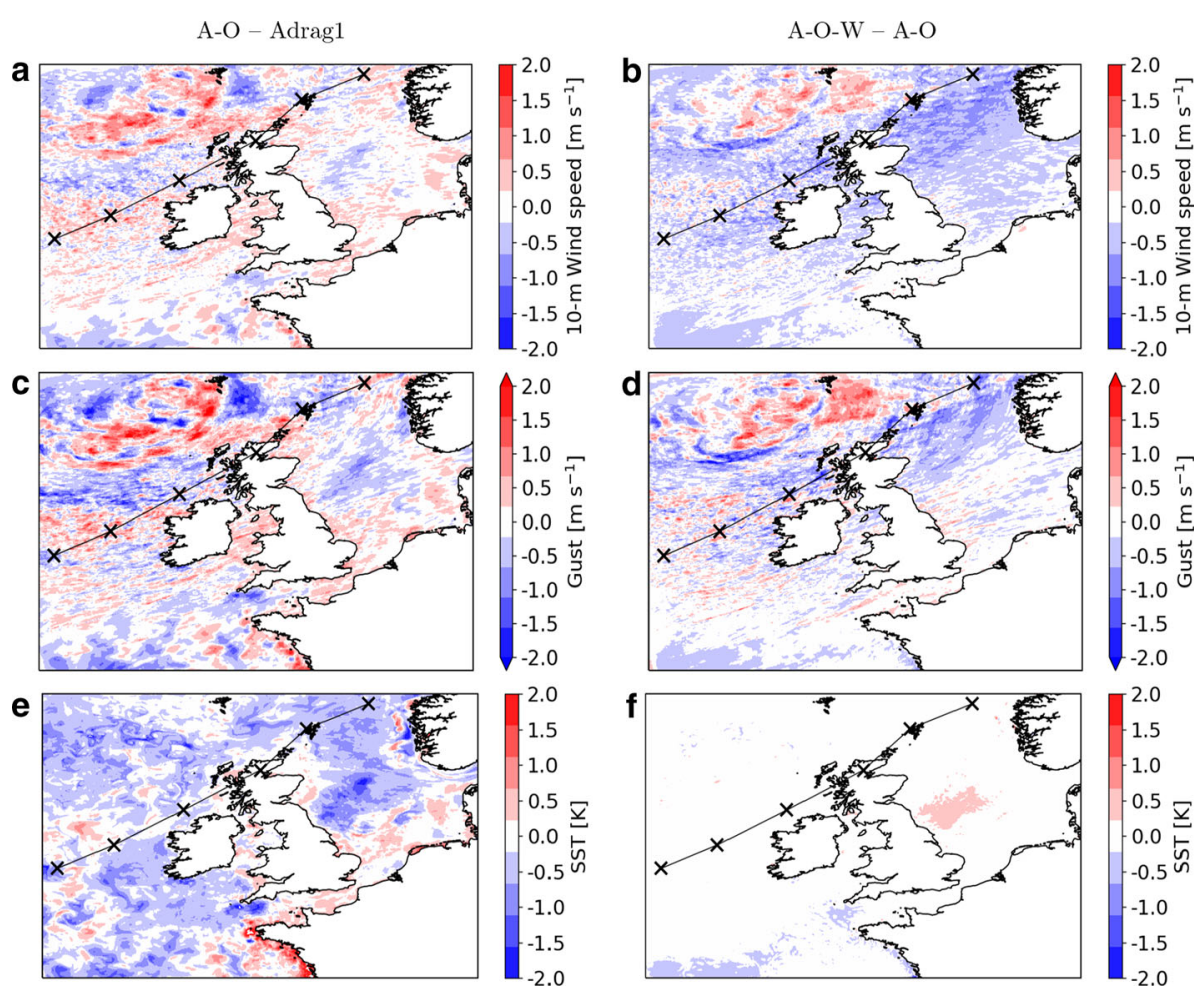

Fig. 6 Maps of differences between A-O and Adrag1 simulated a 10-m wind speeds, $\mathbf{c}$ gusts, and e SSTs, and differences between A-O-W and A-O simulated b 10-m wind speeds, $\mathbf{d}$ gusts, and $\mathbf{f}$ SSTs over the whole model domain (masking land) averaged over 19 September 2018. The track of Ali is marked in each panel as in Fig. 3

cold front is characteristic of ETCs (Sinclair et al. 2010). The model-output MABL height is diagnosed using a "dynamic criterion" (Lock et al. 2013), according to which the boundary layer corresponds to the model-level height where the Richardson number $R i$ exceeds the critical threshold of 0.25 . The boundary-layer profiles (Fig. 7b, c) reveal that the MABL simulated by Adrag 1 is unstable at this point and time, being characterized by a negative near-surface gradient of potential temperature and a strong wind shear.

The A-O configuration yields a weaker near-surface gradient of potential temperature than that simulated by the Adrag1 configuration. This is associated with reduced wind speeds at $200 \mathrm{~m}$ but approximately the same surface wind speeds, and therefore a reduced wind-speed gradient (Fig. 7b, c), and leads to a MABL height of $780 \mathrm{~m}$, reduced from the $1100 \mathrm{~m}$ diagnosed in the Adrag1 simulation. The resulting decreased MABL instability simulated by the A-O configuration is most likely caused by the reduction of SST in the region of the North Sea located underneath the cold sector. Coupling to the wave model and changing the atmospheric drag parametrization both reduce the potential temperature gradients near the surface, leading to a small reduction in instability (comparing A-O to A-O-W) and a larger change from an unstable (Adrag1) to a neutral (Adrag2) surface layer, as inferred from the vertical potential temperature gradients (Fig. 7b). These changes are associated with similar magnitude increases in the wind-shear turbulence and hence with diagnosed MABL height (compare the $\mathrm{A}-\mathrm{O}-\mathrm{W}$ to the $\mathrm{A}-\mathrm{O}$ results and the Adrag 1 to the Adrag2 results). The increased 

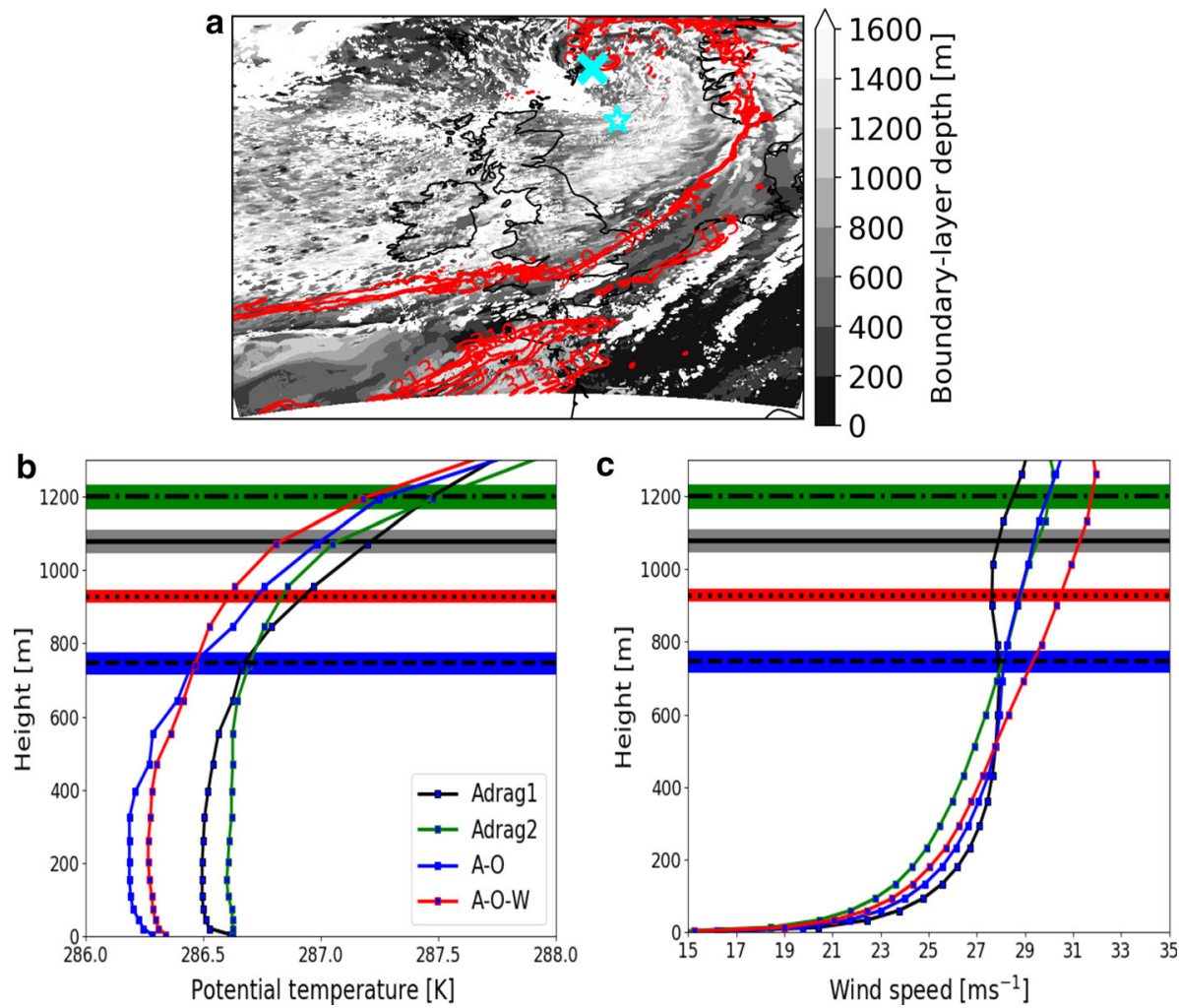

Fig. 7 a Selected $850-\mathrm{hPa}$ equivalent potential temperature contours (307, 310, and $313 \mathrm{~K})$ at 1800 UTC 19 September 2018 overlaying the boundary-layer depth obtained from the Adrag1 simulation. The cold front lies along the strong thermal gradient between Norway and southern England with the short occluded front extending northwards, wrapping round the cyclone centre beyond the domain shown. The mean sea-levelpressure minimum of Ali is denoted by a cyan cross. The cyan star corresponds to the site of the profiles of $\mathbf{b}$ potential temperature and $\mathbf{c}$ wind speed (all profiles averaged over $5 \times 5$ grid cells). The lowest height value of each of the profiles correspond to the bottom UKC4 model- level height. Horizontal lines in $\mathbf{b}, \mathbf{c}$ represent the boundary-layer height diagnosed as the model-level height where the Richardson number exceeds the critical Richardson number $R i_{\text {crit }}=0.25$. Horizontal grey, green, blue, and red filled strips represent the standard error associated with the boundary-layer height diagnosed by each UKC4 configuration

turbulent eddies likely enhance momentum transfer from the air to the sea, leading to the reduction in near-surface wind speeds already noted in Fig. 6 b.

To better understand how the momentum-flux enhancements depend on the numerical modelling of air-sea surface exchange, the maps of the surface MABL characteristics of the A-O-W and the Adrag2 simulations are compared to those of the A-O simulation. Coupling to waves enhances momentum fluxes in the whole region extending south of the track of Ali (Fig. 8b), where reductions in the range of moderate to extreme 10-m wind speeds occur (see Fig. 6b). The young wave ages, corresponding in Fig. 8a to $c_{p} / u_{*}$ values less than 20 , indicate that the sea is covered by young growing waves that enhance the Charnock coefficients by up to 0.02 (see Fig. 8c), which means that the Charnock coefficients increase nearly three times from the constant value $\alpha=0.011$ used by the Adrag 1 and A-O simulations to $\alpha=0.031$, with corresponding enhancements in the roughness length $z_{0}$ by up to $1.5 \times 10^{-3} \mathrm{~m}$ (see Fig. 8d). The increase in the $z_{0}$ is associated with a larger momentum loss at the air-sea 

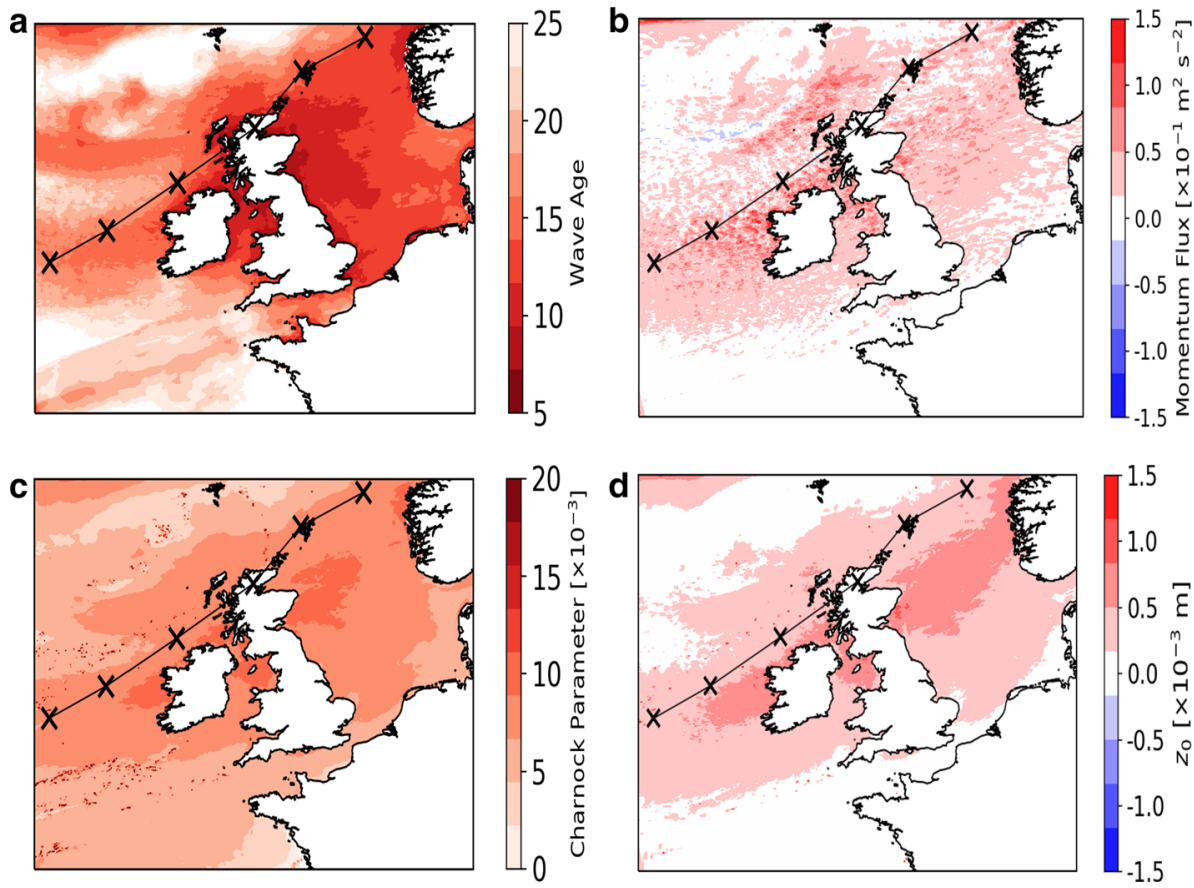

Fig. 8 a Map of wave age in the A-O-W simulation, and maps of differences between the A-O-W and A-O simulations of $\mathbf{b}$ momentum flux, $\mathbf{c}$ Charnock parameter, and $\mathbf{d}$ surface roughness, $z_{0}$, all averaged over 19 September 2018. The non-dimensional wave age is computed as $c_{p} / u_{*}$ where $c_{p}$ is the phase speed of the peak of wave spectrum as defined by Cohen and Belcher (1999) and Sullivan et al. (2008). Ali's track is marked in each panel as in Fig. 3

interface compared with the A-O simulation, resulting in lower wind speeds. This suggests that the waves give rise to a force proportional to the wave-induced stress, which effectively acts as frictional drag at the air-sea interface. Similar results were documented by Janssen (1989), Doyle (1995, 2002), Wahle et al. (2017) and Varlas et al. (2017).

The new drag parametrization used in the Adrag2 simulation enhances the momentum fluxes in the whole region south of the track of Ali compared with those in the A-O simulation (Fig. 9b), leading to a reduction in the moderate to extreme surface wind speeds, which is similar to that found by comparing the A-O-W and the A-O simulations (compare Fig. 9a and $6 \mathrm{~b}$ ). Hence, the new drag parametrization must produce a frictional surface stress at the air-sea interface, which is comparable in size to that induced by the growing young waves in the A-O-W simulation. To verify this, the dependence of the drag coefficient $C_{\mathrm{D}}$ on the $10-\mathrm{m}$ wind speed is presented for the four different UKC4 configurations in the two different sea regions, both south of the track of Ali, marked by the two black dots in Fig. 9a: one located in the Atlantic Ocean, off the west coast of Ireland, and the other one located in the northern North Sea. A close inspection of Fig. 10a, b shows that in the range 5-27 $\mathrm{m} \mathrm{s}^{-1}$ the drag coefficients $C_{\mathrm{D}}$ of the A-O-W and Adrag2 parametrizations increase with the 10-m wind speed more steeply than those produced by the Adrag 1 and A-O parametrizations, therefore leading to a larger surface stress at the air-sea interface. The fact that the gradient of $C_{\mathrm{D}}$ for Adrag2 is even a little steeper than for A-O-W explains the corresponding slightly larger reductions in surface wind speed observed for the Adrag2 parametrization. In the Atlantic 

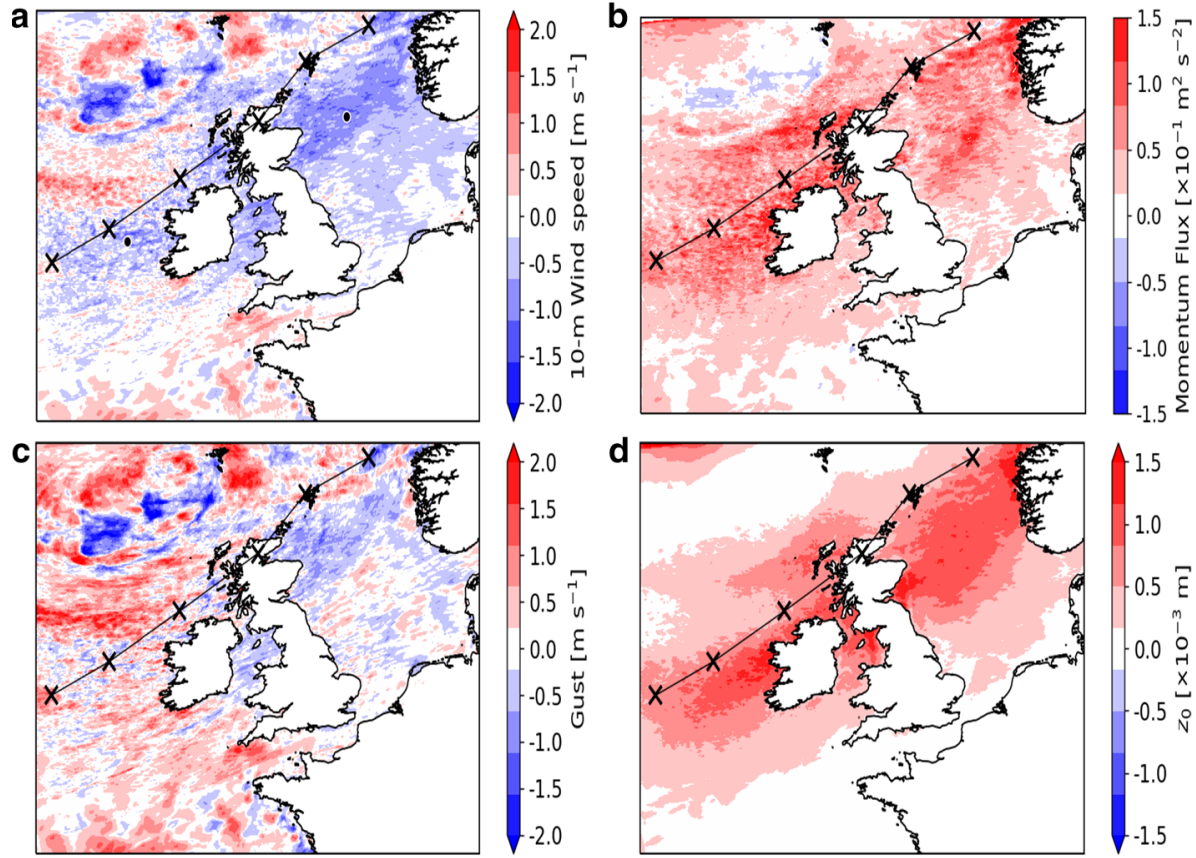

Fig. 9 Maps of differences between Adrag2 and A-O simulations of a 10-m wind speed, b momentum flux, c gusts, d surface roughness, $z_{0}$, and averaged over 19 September 2018 . The track of Ali is marked in each panel as in Fig. 3

Ocean region considered in Fig. 10b, modelled 10-m wind speeds reach values above $27 \mathrm{~m} \mathrm{~s}^{-1}$ where the implementation of the Adrag2 cap on the magnitude of $C_{\mathrm{D}}$ is relevant. Here, there is a suggestion that the A-O-W $C_{\mathrm{D}}$ also seems to flatten above $27 \mathrm{~m} \mathrm{~s}^{-1}$, although at a slightly lower value $\left(C_{\mathrm{D}}=2.8 \times 10^{-3}\right)$ indicating that the atmosphere-only Adrag2 is likely capable of mimicking the physics of the air-sea surface exchange incorporated in the atmosphere-ocean-wave configuration for the whole range of the simulated wind speeds.

The comparison, in the region of greatest surface roughness, of vertical cross-sections of the differences in wind speed and turbulence kinetic energy between $\mathrm{A}-\mathrm{O}-\mathrm{W}$ and $\mathrm{A}-\mathrm{O}$, and between Adrag2 and A-O (not shown), revealed that the wind-speed differences spread up to $8 \mathrm{~km}$ (near the tropopause), but are contained within the cyclone extent. Part of the cyclone's energy is dissipated through enhanced momentum loss at the air-sea interface, offering an explanation for the reduction of the pressure minimum of Ali (see Sect. 3.2) as well as likely leading to its quicker decay, in line with Katsafados et al. (2016).

Compared with the impacts on the 10-m wind speed, both coupling to waves and using the Adrag2 new drag parametrization reduces the gusts less in the regions contiguous with the track of Ali (compare Figs. 6d and 9c). In these regions, the comparatively weak reduction in gusts arises from the formulation of the MetUM gust parametrization (Eq. 2), which is a sum of two terms, one representing the 10-m wind speeds and the other taking into account the friction velocity and surface roughness. Thus, a reduction of $2 \mathrm{~m} \mathrm{~s}^{-1}$ in $10-\mathrm{m}$ wind speed due to coupling to waves or the new drag parametrization is balanced by the increase in friction velocity and aerodynamic roughness in regions contiguous to the track of Ali (see Figs. 8d and 9d), leading to weaker simulated gusts. However, in the north-west quadrant 

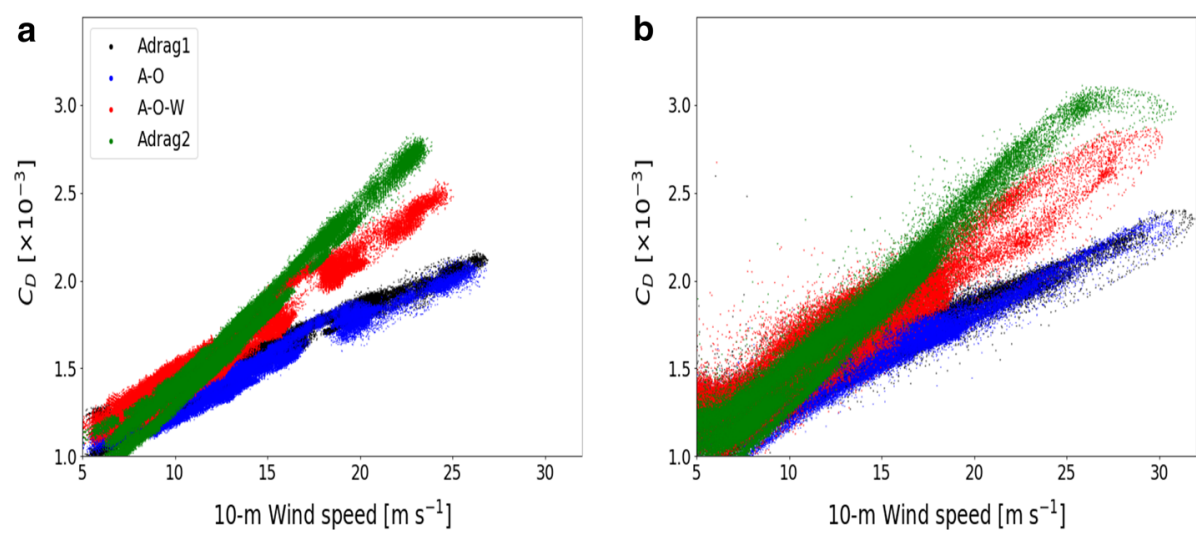

Fig. 10 Drag coefficient dependence on $10-\mathrm{m}$ wind speeds computed as the value of $C_{\mathrm{D}}=\tau / \rho U_{10}^{2}$ over a $15 \times 15$ grid-cell area centred on points in the a North Sea $\left(58.2^{\circ} \mathrm{N}, 0.9^{\circ} \mathrm{E}\right)$ for the Adrag1 (black), A-O (blue), A-O-W (red), and Adrag2 (green) parametrizations, and b North Atlantic Ocean $\left(52.98^{\circ} \mathrm{N}, 12.46^{\circ} \mathrm{W}\right)$ configurations. Scatter points at hourly intervals from 0000 UTC 17 September to 0000 UTC 20 September 2018

of the model domain, far from the track of Ali, the Adrag2 and A-O-W simulations yield localized increases and decreases in gusts of comparable magnitude to the corresponding changes in 10-m wind speeds. Again, this can be explained as arising from the MetUM gust parametrization, according to which the negligible change in aerodynamic roughness implies gusts only depend on changes in 10-m wind speeds.

\subsection{Impact of Coupling and Using a New Drag Scheme on Forecast Bias}

The biases in the SST and 10-m wind speeds are (1) assessed for the four UKC4 configurations over the case-study period as time series of a domain-averaged bias (Fig. 11) and (2) compared using spatial distributions of time-averaged root-mean-square error for one simulation relative to another simulation as illustrated in Fig. 12. Only five stations from the analyzed database reported gust values over the UK consistently enough in time to be statistically significant across the case-study period. Thus a bias plot for gusts is not included here.

Figure 11a shows that the magnitude of the spatially averaged $10-\mathrm{m}$ wind-speed bias is larger over sea-observation sites than over land observation sites with values up to $3 \mathrm{~m} \mathrm{~s}^{-1}$. Over land-observation sites the biases for the four UKC4 simulations are indistinguishable and generally positive with values up to $\approx 1 \mathrm{~m} \mathrm{~s}^{-1}$; over sea-observation sites, the biases in the A-O-W and Adrag2 simulations are typically less than those in the Adrag1 and A-O simulations where the biases are positive and vice versa, consistent with the reduced wind speeds found in these simulations.

The spatially averaged SST biases (Fig. 11b) vary with time between about $-0.5 \mathrm{~K}$ to $1 \mathrm{~K}$. As shown in Fig. 5c, the SSTs for the A-O and A-O-W simulations are similar and generally cool with time, diverging from the fixed SSTs in the atmosphere-only simulations. As the SSTs in the A-O and A-O-W simulations cool, the associated biases improve, changing from generally positive to varying about zero (Fig. 11b). This contrasts with the biases for the atmosphere-only simulations which, despite the variability with time, stay generally positive. These results corroborate the findings of Lewis et al. (2018) in which coupling to the ocean reduced the SST bias by up to $1 \mathrm{~K}$. 

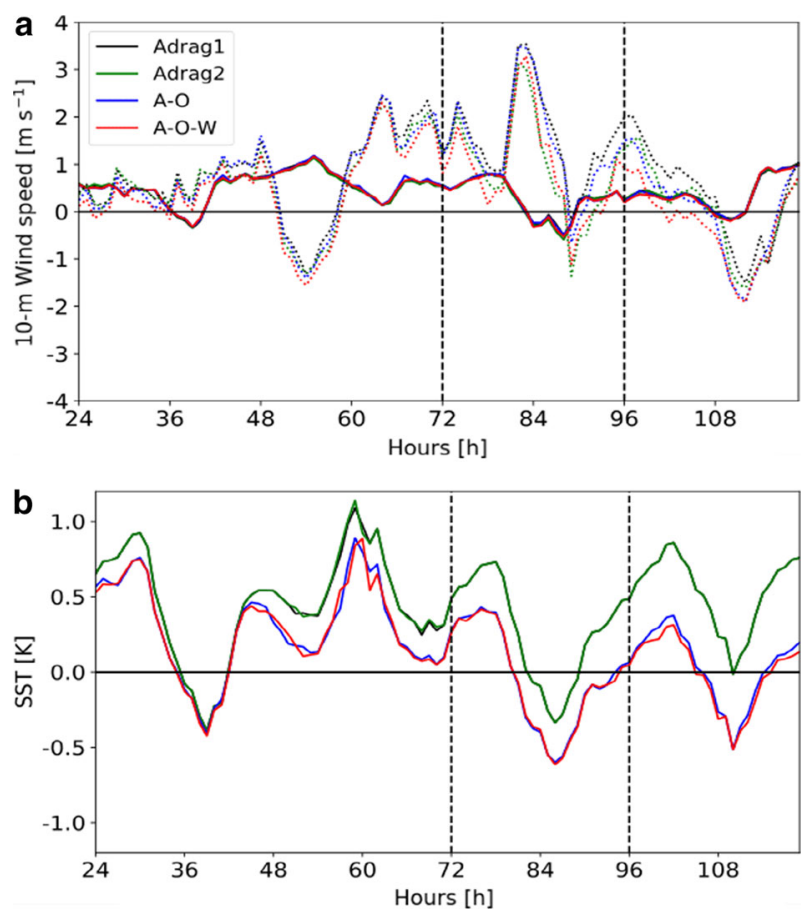

Fig. 11 Time series of spatially averaged biases for the different model simulations of a 10-m wind speed across land-only (solid lines) and sea-only (dashed lines) observation sites (600 and 60 respectively) and b SST (10 observation sites) for 17-20 September 2018. The lines correspond to the Adrag1 (black), Adrag2 (green), A-O (blue), and A-O-W (red) simulations. The Adrag1 and Adrag2 lines are identical in panel b

The impact of coupling to ocean, of coupling to waves, and of the new Adrag2 parametrization on 10-m wind-speed $R M S E_{\text {rel }}$ forecast skill is quantified by computing the value of the $R M S E_{\text {rel }}$ of $\mathrm{A}-\mathrm{O}$ relative to Adrag $1, \mathrm{~A}-\mathrm{O}-\mathrm{W}$ relative to $\mathrm{A}-\mathrm{O}$, and $\mathrm{A}-\mathrm{O}-\mathrm{W}$ relative to Adrag2. As can be seen from the prevalence of light over dark coloured dots in Fig. 12a, partially coupling to ocean neither appreciably improves nor degrades the 10 -m wind-speed forecast compared with the atmosphere-only Adrag 1 configuration. In contrast, the prevalence of dark green dots over the North Sea in Fig. 12b highlights that coupling to waves improves the $10-\mathrm{m}$ wind-speed-forecast skill by up to $20 \%$ over the ocean-grid cells (comparing the $\mathrm{A}-\mathrm{O}-\mathrm{W}$ and $\mathrm{A}-\mathrm{O}$ simulations). However, changes over land are much smaller and show, at most, a small reduction in skill in the few areas of the UK indicated by the pink dots. Compared with the atmosphere-only Adrag2 simulation, the fully coupled A-O-W configuration slightly improves the 10-m wind-speed forecast in the northern part of the North Sea, but degrades it in the central part of the North Sea (Fig. 12c). Hence, for most of the observation sites, the atmosphere-only Adrag2 simulation with the new drag parametrization is able to achieve the same improvement in 10-m wind-speed-forecast skill as that obtained from fully coupling the atmosphere to ocean and waves (A-O-W) with the benefit of saving $25 \%$ of the computational cost (estimated in node hours per simulation day, see Table 1). 
A-O relative to Adrag1

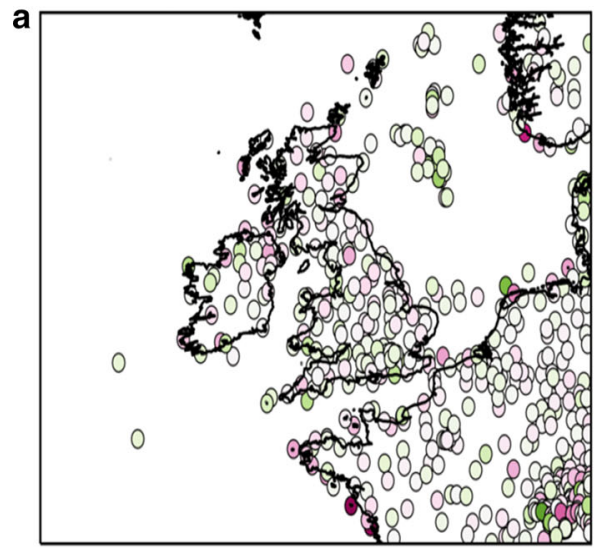

A-O-W relative to Adrag1

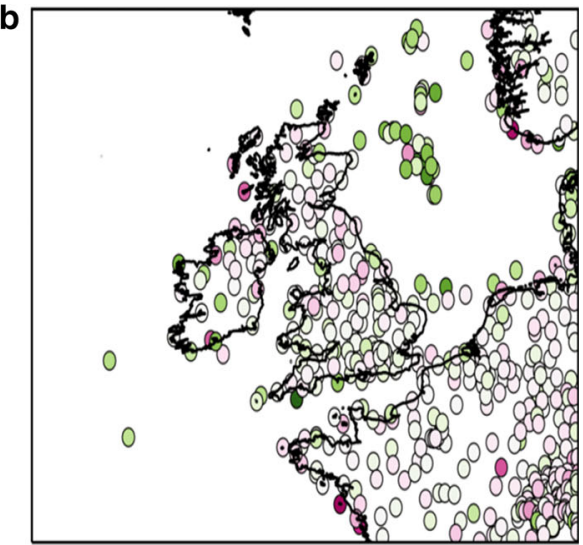

C

A-O-W relative to Adrag2

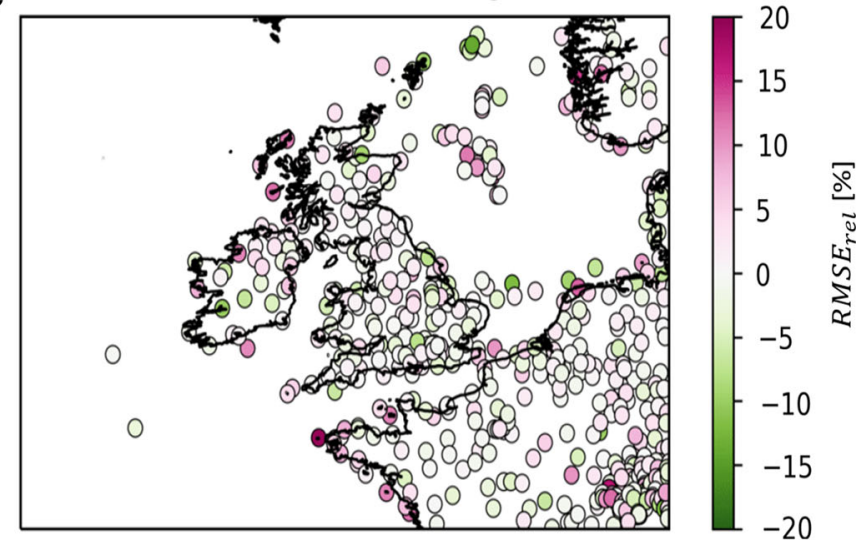

Fig. 12 Percentage difference in wind speed $R M S E_{\text {rel }}$ for a A-O relative to Adrag1, b A-O-W relative to Adrag1, and c A-O-W relative to Adrag2 averaged over 17-20 September 2018

\section{Conclusions}

Prior work has documented the importance of a high-fidelity representation of air-sea surface exchanges in NWP models to obtain an accurate forecast of extreme surface wind speeds (Janssen 2004). Usually, this has been achieved either by providing uncoupled atmosphereonly NWP models with a suitable boundary-layer parametrization [e.g., the UKV system (Tang et al. 2013)] or by setting up a coupled multi-model NWP system which integrates the feedbacks of ocean and wave models with an atmosphere-only model [e.g., CHAOS2-way system developed by Katsafados et al. (2016)]. In this context, the UK Met Office developed the UKC4 multi-model system, which couples the atmospheric (MetUM) model (and JULES land-surface model), with the ocean (NEMO), and wave (WAVEWATCH III) models. The UKC4 system is a robust and flexible research tool characterized by different coupling options at kilometre-scale resolution (Lewis et al. 2018, 2019).

The purpose of the current study was to quantify the sensitivity of extreme surface wind speeds to air-sea surface exchange by using the UKC4 multi-model system in coupled and 
uncoupled modes. The extreme weather period of 17-20 September 2018 (which included ETCs Helene, Ali, and Bronagh), was used as the case study. Four UKC4 configurations were used: the uncoupled atmosphere-only configuration Adrag1, provided with the operational UKV drag parametrization; the uncoupled atmosphere-only configuration Adrag2, provided with a new drag parametrization based on the COARE 4.0 drag parametrization corrected with the Donelan (2018) cap and decrease the drag coefficient at high wind speeds; the partially coupled A-O atmosphere-ocean configuration; and the fully coupled $\mathrm{A}-\mathrm{O}-\mathrm{W}$ atmosphereocean-wave configuration.

For this case study, coupling to the ocean (A-O configuration) does not strongly affect the 10 -m wind speeds, but it does have an important impact on SSTs, reducing them by up to $0.5 \mathrm{~K}$ compared with the persisted SST field used in the two atmosphere-only Adrag1 and Adrag2 configurations. Unlike coupling to ocean, coupling to waves reduces the $10-\mathrm{m}$ wind speeds by up to $2 \mathrm{~m} \mathrm{~s}^{-1}$ compared with the atmosphere-only Adrag1 and partially coupled A-O configurations. The atmosphere-only Adrag2 configuration provides equivalent reductions in wind speeds. Comparison of the boundary-layer profiles at a point in the North Sea, where the impacts of wave coupling and Adrag2 parametrization scheme are most prominent, demonstrate that the Adrag2 configuration is capable of simulating the same enhancement of the air-sea turbulent momentum flux as the fully coupled A-O-W configuration.

The investigation of A-O-W air-sea momentum-flux enhancements revealed that young growing waves extract momentum and energy from the overlying atmospheric flow, increasing the frictional drag at the sea surface and thus reducing near-surface wind speeds. As an effect of the increase in the aerodynamic roughness of this evolving sea state, Charnock parameter values simulated by the WAVEWATCH III model, and then passed to the MetUM, exceed the semi-empirical constant value of $\alpha=0.011$ set in the uncoupled and partially coupled configurations. Although an increase of comparable size in aerodynamic roughness and frictional drag over the sea due to young growing waves simulated by coupling a NWP model to a wave component has already been documented by Varlas et al. (2017), Wahle et al. (2017), and Lewis et al. (2018, 2019), here an equivalent increase in aerodynamic roughness and frictional drag has also been achieved by the atmosphere-only Adrag2 simulation. It was verified that the Adrag2 drag coefficient linear growth with $10-\mathrm{m}$ wind speeds is significantly steeper than that of the UKV drag coefficient in the range 5-27 m s${ }^{-1}$ and above $27 \mathrm{~m} \mathrm{~s}^{-1}$ it limits the value of $C_{\mathrm{D}}$ at $C_{\mathrm{D}}=3 \times 10^{-3}$, effectively mimicking the physics of the momentum air-surface exchange incorporated in the fully coupled A-O-W configuration.

The increase in surface roughness and surface friction exhibited by the A-O-W and Adrag2 simulations generates a more turbulent and thus deeper MABL resulting, in both configurations, in areas of enhanced gustiness across the boundary layer. However, this effect is balanced by an increase in friction velocity resulting in a modest impact on gust values at the surface, regardless of the changes in the simulated physics across the configurations. Moreover, the increased aerodynamic roughness in the A-O-W and Adrag2 configurations affects the cyclone's vertical structure and increases the mean sea level pressure by up to $2 \mathrm{hPa}$ through dissipation of its energy at the air-sea interface.

Coupling to the ocean (in both the A-O and A-O-W simulations) improves the SST bias compared with the atmosphere-only Adrag1 and Adrag2 simulations, in agreement with results from Lewis et al. (2018), but has a negligible impact on the 10-m wind-speed bias. However, coupling to waves (A-O-W) and using the new drag parametrization (Adrag2) improves the wind-speed bias over sea-observation sites. Fully coupling (the A-O-W simulation) improved the RMSE $\mathrm{E}_{\text {rel }}$ forecast skill of 10 -m wind speeds (over open waters) by up to $20 \%$ compared with the atmosphere-only Adrag 1 and partially coupled A-O simulations, in agreement with the literature (Wahle et al. 2017; Varlas et al. 2017). The same forecast-skill 
improvements relative to the A-O and Adrag1 simulations are achieved by the uncoupled Adrag 2 configuration, with the advantage of saving $25 \%$ of the computational cost, estimated in node hours per simulation day, of running a fully coupled A-O-W configuration.

A limitation of this research is the short length of the time period investigated. It would be useful to repeat the study over longer time periods to determine the statistical significance of the results. Moreover, although coupling or changing the drag parametrization reduces the model error in 10-m wind speeds, the relatively small improvements (respect to the biases) imply that errors in initial and/or lateral boundary conditions, or model physics parametrizations, dominate over errors in air-sea coupling. However, taken together, our results demonstrate that, for this case study, an atmosphere-only model provided with the new drag parametrization based on the COARE 4.0 parametrization with the Donelan (2018) cap and drag reduction (as that used in Adrag2) has the same physical and numerical impacts on the wind speeds in ETCs as a fully coupled model system, with the notable advantage of reducing the computational cost associated with the ocean and wave model components.

Acknowledgements Emanuele S. Gentile's contribution was funded through a Natural Environment Research Council (NERC) Industrial CASE studentship in collaboration with the Met Office (NE/R007640/1). The model simulations outputs used are archived at the Met Office. Please contact the authors for details. We would like to thank three anonymous reviewers for their comments which helped to improve this paper.

Open Access This article is licensed under a Creative Commons Attribution 4.0 International License, which permits use, sharing, adaptation, distribution and reproduction in any medium or format, as long as you give appropriate credit to the original author(s) and the source, provide a link to the Creative Commons licence, and indicate if changes were made. The images or other third party material in this article are included in the article's Creative Commons licence, unless indicated otherwise in a credit line to the material. If material is not included in the article's Creative Commons licence and your intended use is not permitted by statutory regulation or exceeds the permitted use, you will need to obtain permission directly from the copyright holder. To view a copy of this licence, visit http://creativecommons.org/licenses/by/4.0/.

\section{References}

Belcher SE, Hunt JCR (1993) Turbulent shear flow over slowly moving waves. J Fluid Mech 251:109-148

Beljaars A (1987) The influence of sampling and filtering on measured wind gusts. J Atmos Ocean Technol 4:613-626

Best MJ, Pryor M, Clark DB, Rooney GG, Essery RLH, Menard CB, Edwards J, Hendry MA, Porson A, Gedney N, Mercado LM, Sitch S, Blyth E, Boucher O, Cox PM, Grimmond CSB, Harding RJ (2011) The joint UK land environment simulator (JULES), model description-Part 1: energy and water fluxes. Geosci Model Dev 4:677-699

Browning KA, Roberts NM (1994) Structure of a frontal cyclone. Q J R Meteorol Soc 120:1535-1557

Charnock H (1955) Wind stress on a water surface. Q J R Meteorol Soc 81:639-640

Cohen JE, Belcher SE (1999) Turbulent shear over fast moving waves. J Fluid Mech 386:345-371

Cook P, Renfrew IA (2014) Aircraft-based observations of air-sea turbulent fluxes around the British Isles. Q J R Meteorol Soc 141:139-152

Craig M (2003) A once in 50 year wind speed map for Europe derived from mean sea level pressure measurements. J Wind Eng Ind Aerodyn 91:1813-1826

Csanady G (2001) Air-sea interaction: laws and mechanisms. Cambridge University Press, Cambridge

Donelan MA (1982) The dependence of the aerodynamic drag coefficient on wave parameters. In: Proceedings of the First international conference on meteorology and the air/sea interaction of the coastal zone, The Hague, The Netherlands. American Meteorological Society, Boston, pp 381-387

Donelan MA (2018) On the decrease of the oceanic drag coefficient in high winds. J Geophys Res 123:14851501

Donelan MA, Dobson FW, Smith SD, Anderson RJ (1993) On the dependence of sea surface roughness on wave development. J Phys Oceanogr 23:2143-2149

Donlon CJ, Martin M, Stark JD, Roberts-Jones J, Fiedler E, Wimmer W (2012) The operational sea surface temperature and sea ice analysis. Remote Sens Environ 116:140-158 
Doyle JD (1995) Coupled ocean wave/atmosphere mesoscale model simulations of cyclogenesis. Tellus 47:766-778

Doyle JD (2002) Coupled atmosphere-ocean wave simulations under high wind conditions. Mon Weather Rev 130:3087-3099

Earl N, Dorling S (2013) 1980-2010 Variability in U.K. surface wind climate. J Clim 26:1172-1191

Earl N, Dorling S, Starks M, Finch R (2017) Subsynoptic-scale features associated with extreme surface gusts in UK extratropical cyclone events. Geophys Res Lett 44:3932-3940

Edwards JM (2007) Oceanic latent heat fluxes: consistency with the atmospheric hydrological and energy cycles and general circulation modelling. J Geophys Res 112:D06115

Graham JA, O’Dea E, Holt J, Polton J, Hewitt HT, Furner R, Guihou K, Brereton A, Arnold A, Wakelin S, Castillo Sanchez JM, Mayorga Adame CG (2018) AMM15: a new high-resolution NEMO configuration for operational simulation of the European north-west shelf. Geosci Model Dev 11:681-696. https://doi. org/10.5194/gmd-11-681-2018

Hewston R, Dorling S (2011) An analysis of observed daily maximum wind gusts in the UK. J Wind Eng Ind Aerodyn 91:845-856

Hsu J, Lien RC, D'Asaro EA, Sanford T (2017) Estimates of surface wind stress and drag coefficients in Typhoon Megi. J Phys Oceanogr 47:545-565

Janssen P (1989) Wave-induced stress and the drag of air flow over sea waves. J Phys Oceanogr 19:745-772

Janssen P (1991) Quasi-linear theory of wind-wave generation applied to wave forecasting. J Phys Oceanogr 21:1631-1642

Janssen P (2004) The interaction of ocean waves and wind. Cambridge University Press, Cambridge

Jenkins A, Paskyabi B, Fer M, Gupta A, Adakudlu M (2012) Modelling the effect of ocean waves on the atmospheric and ocean boundary layers. Energy Procedia 24:166-175

Katsafados P, Papadopoulos A, Korres G, Varlas G (2016) A fully coupled atmosphere-ocean-wave modeling system for the Mediterranean Sea: interactions and sensitivity to the resolved scales and mechanisms. Geosci Model Dev 9:161-173

Klawa M, Ulbrich U (2003) A model for the estimation of storm losses and the identification of severe winter storms in Germany. Nat Hazards Earth Sys Sci 3:725-732

Komen GJ, Cavaleri L, Donelan M, Hasselmann K, Hasselmann S, Janssen PAE (1994) Dynamics and modelling of ocean waves. Cambridge University Press, Cambridge

Lewis HW, Castillo Sanchez JM, Graham J, Saulter A, Bornemann J, Arnold A, Fallmann J, Harris C, Pearson D, Ramsdale S, Martnez-de la Torre A, Bricheno L, Blyth E, Bell VA, Davies H, Marthews TR, O'Neill C, Rumbold H, O’Dea E, Brereton A, Guihou K, Hines A, Butenschon M, Dadson SJ, Palmer T, Holt J, Reynard N, Best M, Edwards J, Siddorn J (2018) The UKC2 regional coupled environmental prediction system. Geosci Model Dev 11:1-42

Lewis HW, Sanchez JMC, Arnold A, Fallmann J, Saulter A, Graham J, Bush M, Siddorn J, Palmer T, Lock A, Edwards J, Bricheno L, de la Torre AM, Clark J (2019) The UKC3 regional coupled environmental prediction system. Geosci Model Dev 12:6

Lionello JD, Malguzzi P, Buzzi A (1998) Coupling between the atmospheric circulation and the ocean wave field: an idealized case. J Phys Oceanogr 28:161-177

Lock A, Edwards J, Smith R (2013) Unified model documentation paper 24: the parametrization of boundary layer processes. Technical report, UM version 8.6, Met Office

Madec G (2016) NEMO reference manual 3_6_STABLE:NEMO ocean engine. Note du Pôle de modélisation, Institut Pierre-Simon Laplace (IPSL), France

MetOffice (2018) Storm Ali

Miles JW (1957) On the generation of surface waves by shear flows. J Fluid Mech 3:185-204

Panofsky H, Tennekes H, Lenschow D, Wyngaard J (1977) The characteristics of turbulent velocity components in the surface layer under convective conditions. Boundary-Layer Meteorol 11:355-361

Phillips OM (1957) On the generation of waves by turbulent wind. J Fluid Mech 57:417-445

Powell M, Vickery P, Reinhold T (2003) Reduced drag coefficient for high wind speeds in tropical cyclones. Nature 422:279-283

Ricchi A, Miglietta MM, Barbariol F, Benetazzo A, Bergamasco A, Bonaldo D, Cassardo C, Falcieri F, Modugno C, Russo A, Sclavo M, Carniel S (2017) Sensitivity of a Mediterranean Tropical-Like Cyclone to different model configurations and coupling strategies. Atmosphere 8:1-23

Rockel B, Will A, Hense A (2008) The Regional Climate model COSMO-CLM (CCLM). Meteorol Z 17:347348

Schultz DM, Bosart LF, Colle BA, Davies HC, Dearden C, Keyser D, Martius O, Roebber PJ, Steenburgh WJ, Volkert H, Winters AC (2019) Extratropical cyclones: a century of research on meteorology's centerpiece. Meteorol Monogr 59:16.1-16.56 
Sinclair V, Belcher S, Gray S (2010) Synoptic controls on boundary-layer characteristics. Boundary-Layer Meteorol 134:387-409

Skamarock WC, Klemp JB (2008) A time-split non-hydrostatic atmospheric model for weather research and forecasting applications. J Comput Phys 227:3465-3485

Smith S (1988) Coefficients for sea surface wind stress, heat flux, and wind profiles as a function of wind speed and temperature. J Geophys Res 93:15467-15472

Smith SD, Anderson RJ, Oost W (1992) Sea surface wind stress and drag coefficients: the HEXOS results. Boundary-Layer Meteorol 60:109-142

Sullivan PP, Edson J, Hristov T, McWilliams J (2008) Large-eddy simulations and observations of atmospheric marine boundary layers above nonequilibrium surface waves. J Atmos Sci 65:1225-1245

Sullivan PP, McWilliams JC, Patton EG (2014) Large-eddy simulation of marine atmospheric boundary layers above a spectrum of moving waves. J Atmos Sci 71:4001-4027

Tang Y, Lean HW, Bornemann J (2013) The benefits of the Met Office variable resolution NWP model for forecasting convection. Meteorol Appl 20:417-426

Tonani M, Sykes P, King RR, McConnel N, Péquignet AC, O’Dea E, Graham JA, Polton J, Siddorn J (2019) The impact of a new high-resolution ocean model on the Met Office North-West European Shelf forecasting system. Ocean Sci 15:1133-1158

Varlas G, Katsafados P, Papadopoulos A, Gerasimos K (2017) Implementation of a two-way coupled atmosphere-ocean wave modeling system for assessing air-sea interaction over the Mediterranean Sea. Atmos Res 208:201-217

Wahle K, Staneva J, Koch W, Fenoglio-Marc L, Ho-Hagemann H, Stanev E (2017) An atmosphere-wave regional coupled model: improving predictions of wave heights and surface winds in the southern North Sea. Ocean Sci 13:289-301

Walters D, Boutle I, Brooks M, Melvin T, Stratton R, Vosper S, Wells H, Williams K, Wood N, Allen T, Bushell A, Copsey D, Earnshaw P, Edwards J, Gross M, Hardiman S, Harris C, Heming J, Klingaman N, Levine R, Manners J, Martin G, Milton S, Mittermaier M, Morcrette C, Riddick T, Roberts M, Sanchez C, Selwood P, Stirling A, Smith C, Suri D, Tennant W, Vidale PL, Wilkinson J, Willett M, Woolnough S, Xavier P (2017) The Met Office Unified Model Global Atmosphere 6.0/6.1 and JULES Global Land 6.0/6.1 configurations. Geosci Model Dev 10:1487-1520. https://doi.org/10.5194/gmd-10-1487-2017

WW3DG WIDG (2016) User manual and system documentation of WAVEWATCH III®, version 5.16, Tech. Note 329. NOAA/NWS/NCEP/MMAB, College Park, MD, USA, 326 pp. + Appendices

Publisher's Note Springer Nature remains neutral with regard to jurisdictional claims in published maps and institutional affiliations. 